\title{
Involving young people in the care and support of people living with HIV/AIDS in Zambia
}

\author{
Eka Esu-Williams \\ Population Council \\ Katie D. Schenk \\ Population Council \\ Joseph Motsepe \\ Population Council \\ Scott Geibel \\ Population Council \\ Anderson Zulu \\ Population Council
}

Follow this and additional works at: https://knowledgecommons.popcouncil.org/departments_sbsr-hiv

Part of the Demography, Population, and Ecology Commons, Health Policy Commons, Immune System Diseases Commons, International Public Health Commons, Medicine and Health Commons, Public Health Education and Promotion Commons, Social Policy Commons, and the Virus Diseases Commons

How does access to this work benefit you? Let us know!

\section{Recommended Citation}

Esu-Williams, Eka, Katie D. Schenk, Joseph Motsepe, Scott Geibel, and Anderson Zulu. 2004. "Involving young people in the care and support of people living with HIV/AIDS in Zambia," Horizons Final Report. Washington, DC: Population Council. 


\section{Involving Young People in the \\ Care and Support of People Living with HIV/AIDS in Zambia}

\section{Herizons N}




\title{
Involving Young People in the Care and Support of People Living with HIV and AI DS in Zambia
}

\author{
Eka Esu-Williams, Katie Schenk, J oseph Motsepe, \\ Scott Geibel, and Anderson Zulu \\ Horizons/Population Council \\ in collaboration with: \\ Care/Zambia \\ Family Health Trust
}

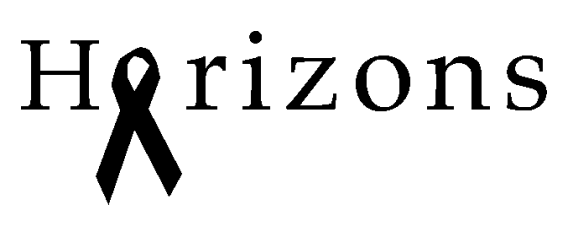

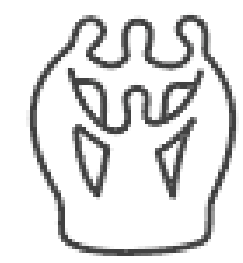

Family Health Trust 
Suggested citation: Esu-Williams, Eka, Katie Schenk, Joseph Motsepe, Scott Geibel, and Anderson Zulu. 2004. "Involving Young People in the Care and Support of People Living with HIV and AIDS in Zambia: Final Report of an Operations Research Study in Luapula and Northern Provinces," Horizons Final Report. Washington, DC: Population Council.

USAID This study was supported by the Horizons Program, which is implemented by the Population Council in collaboration with the International Center for Research on Women, International

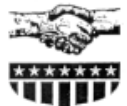
HIV/AIDS Alliance, Program for Appropriate Technology in Health, Tulane University, Family International Development, under the terms of HRN-A-00-97-00012-00. The opinions expressed herein are those of the authors and do not necessarily reflect the views of the U.S. Agency for International Development.

Published in May 2004.

\section{Population Council}

The Population Council is an international, nonprofit, nongovernmental institution that seeks to improve the well-being and reproductive health of current and future generations around the world and to help achieve a humane, equitable and sustainable balance between people and resources. The Council conducts biomedical, social science, and public health research and helps build research capacities in developing countries. Established in 1952, the Council is governed by an international board of trustees. Its New York headquarters supports a global network of regional and country offices.

Copyright (C) 2004 The Population Council Inc.

This document may be reproduced in whole or in part without permission of the Population Council provided full source citation is given and the reproduction is not for commercial purposes.

Horizons Program/Population Council

Communications Unit

4301 Connecticut Ave, NW, Suite 280

Washington, DC 20008

Tel: 202-237-9400

Fax: 202-237-8410

horizons@pcdc.org

www.popcouncil.org/horizons

\author{
Horizons Program/Population Council \\ P.O. Box 411744 \\ Craighall 2024 \\ Johannesburg \\ Tel: 27-11-325-0518 \\ Fax: 27-011-325-0647
}




\section{Acknowledgments}

We especially wish to express our gratitude to the members of the 60 youth clubs in Mansa, Nchelenge, Mporokoso, and Kasama districts, together with their patrons and matrons who worked so hard and showed a great sense of enthusiasm and commitment even under very challenging conditions.

We offer particular thanks to the clients of our services, who took part in the study by opening up their doors to the youth caregivers and taking part in interviews and discussions.

We are also grateful to local community leaders too numerous to mention, from whose inspiration we benefited greatly.

Acknowledgments are also due to the following people who contributed to this report:

Program support:

- Sister Petronella Bweupe, Catholic Diocese of Mansa

- The late Esaya Bukanga, Catholic Archdiocese of Ndola

- The late Mutale Chomba, Horizons /Population Council

- Amos Kasongo, Horizons/Population Council

- Moses Zulu, Horizons/Population Council

Mangala Chambeshi-Moyo and Tamara Fetters of CARE/Zambia were responsible for coordinating the research activities and capacity building in care and support.

Dickstar Kaluba, Collins Mwansa, and Mwape Chalowandya of Family Health Trust were responsible for the HIV prevention training and club development activities.

Data collection supervisors and trainers during the baseline, midterm, and endline surveys were:

- Beck Banda, Youth Forum, Zambia

- Sam Bwalya, Northern Province Health Education Project

- Levyson Chipangula, CARE Zambia

- Kasonde Lwao, CARE Zambia

- Fines Mukonze, CARE Zambia

- Justine Mulenga, District Education Office, Mkporokoso

- The late Aaron Mwale, University of Zambia

- Alice Whitehead, CARE Zambia 
We are particularly grateful to local organizations and individuals in Luapula and Northern provinces for their tremendous support. These include:

- Rhoda Bulezi, Mansa District AIDS Task Force

- W.S. Kasoloko, Ministry of Education, Nchelenge District

- Linda Lahme, Luapula Foundation Mansa

- Denny Luwaya, AIDS Task Force, Nchelenge

- Peggy Mumba, Society for Women Against AIDS, Mansa

- Joseph Mutale, Northern Province Health Education Project

- Mrs. van Andel, Bwafwano Central Board (Mporokoso district)

- District Health Management Teams

- District Inspectors of Schools

- Home-based care teams of the Mansa Catholic Diocese

- Kasama School of Nursing

- Project Concern International

- St. Paul's Mission Hospital

- District AIDS Task Force, Mansa and Nchelenge

Technical, administrative, and editorial support:

- Alison Clarke, Horizons/Population Council

- Margaret Dadian, Horizons/Population Council

- Sherry Hutchinson, Horizons/Population Council

- Winnie Lubasi, Population Council

- Lewis Ndhlovu, Horizons/Population Council

- Nancy Sloan, Population Council

- Ellen Weiss, Horizons/International Center for Research on Women

Reviewers:

- Claudia Daileader Ruland, YouthNet/Family Health International

- Karusa Kiragu, Horizons/PATH 


\section{Table of Contents}

\section{Abbreviations and Acronyms}

\section{Executive Summary}

Introduction 7

HIV and AIDS in Zambia $\quad 7$

$\begin{array}{ll}\text { Care and support in Zambia } & 7\end{array}$

$\begin{array}{lc}\text { Youth anti-AIDS activities } & 8\end{array}$

Background $\quad 9$

$\begin{array}{ll}\text { Aims of the study } & 9\end{array}$

$\begin{array}{ll}\text { Study setting } & 10\end{array}$

$\begin{array}{ll}\text { Study design } & 11\end{array}$

$\begin{array}{lr}\text { Data collection and analysis } & 12\end{array}$

Description of the care and support intervention $\quad 13$

$\begin{array}{ll}\text { Community participation } & 15\end{array}$

$\begin{array}{ll}\text { Study limitations } & 15\end{array}$

$\begin{array}{ll}\text { Results } & 16\end{array}$

$\begin{array}{ll}\text { Profile of respondents } & 16\end{array}$

$\begin{array}{ll}\text { Involvement in HIV prevention activities } & 17\end{array}$

Involvement in HIV caregiving activities $\quad 21$

$\begin{array}{ll}\text { Partnerships } & 26\end{array}$

$\begin{array}{ll}\text { Stigma } & 30\end{array}$

Perceptions of risk, vulnerability, and responsibility 31

Risky behaviors $\quad 35$ 
Conclusions

Recommendations and Next Steps $\quad 47$

$\begin{array}{ll}\text { Care and support interventions } & 47\end{array}$

$\begin{array}{ll}\text { Prevention interventions } & 48\end{array}$

$\begin{array}{ll}\text { References } & 50\end{array}$ 


\section{Abbreviations and Acronyms}

$\begin{array}{ll}\text { AIDS } & \text { acquired immune deficiency syndrome } \\ \text { CBO } & \text { community-based organization } \\ \text { C\&S } & \text { care and support } \\ \text { DHMT } & \text { District Health Management Team } \\ \text { DHS } & \text { Demographic and Health Survey } \\ \text { HBC } & \text { home-based care } \\ \text { HIV } & \text { human immunodeficiency virus } \\ \text { HCW } & \text { health care worker } \\ \text { KAP } & \text { knowledge, attitudes, and practices } \\ \text { MOH } & \text { Ministry of Health } \\ \text { NGO } & \text { nongovernmental organization } \\ \text { OR } & \text { odds ratio } \\ \text { OVC } & \text { orphans and vulnerable children } \\ \text { PLHA } & \text { people/person living with HIV and AIDS } \\ \text { STI } & \text { sexually transmitted infection } \\ \text { TB } & \text { tuberculosis } \\ \text { USAID } & \text { United States Agency for International Development } \\ \text { VCT } & \text { voluntary counseling and testing } \\ \text { WHO } & \text { World Health Organization }\end{array}$





\section{Executive Summary}

\section{Study Description}

Horizons, in collaboration with CARE International and Family Health Trust, conducted a quasiexperimental intervention study to determine which care and support needs of people living with HIV and AIDS and their families could be met by trained youth, and to establish whether youth engaged in formalized care and support activities would increase their adoption of protective behaviors or reduce the stigma faced by members of AIDS-affected households.

The study was conducted in semi-urban and rural communities in two provinces of northern Zambia located 700 to 1,000 kilometers from Lusaka. Thirty clubs in Luapula Province served as intervention sites; an equal number in Northern Province served as comparison sites.

All 60 clubs in both intervention and comparison areas received basic training in club management and HIV prevention, as well as materials for recreational activities (e.g., footballs, netballs, drums). Clubs in the intervention area also received enhanced training in care and support, with an emphasis on how to network with existing resources and services, such as NGOs, programs for orphans and vulnerable children (OVC), clinics, and home-based care (HBC) teams.

In the intervention area, 300 youth club members received training in care and support according to a locally generated curriculum covering a wide variety of topics relating to the needs of HIVpositive people and their families, including a field component and follow-on training and support. Each club received two bicycles to help with transport needs, and a regularly replenished care kit containing items to help the caregivers treat sores and prevent infections.

Quantitative surveys and qualitative data collection exercises were carried out before and after the intervention. Participatory dissemination workshops were conducted with club members and stakeholders to shed light on the emerging results.

\section{Key Findings}

\section{Caregiving activities among youths increased in the intervention area.}

At the first survey round, almost half of both males and females in both areas reported that they recently provided care to a family member or neighbor with a chronic illness. Little change in care activity by respondents was documented in the comparison area at follow-up, while the proportion of youth in the intervention area reporting that they provided care to someone with HIV or AIDS almost doubled by the second survey. For example, club members in the intervention area providing care increased from 47 percent to 82 percent for males and from 41 percent to 78 percent for females $(\mathrm{p}<0.05)$. 


\section{Hgrizons}

Although high at the first round, trained youth caregivers' comfort level in providing care to clients living with HIV and AIDS increased, with females reporting the greatest gains ( 72 percent to 91 percent, $\mathrm{p}<0.05$ ) compared to males (81 percent to 90 percent, $\mathrm{p}<0.05$ ). By the follow-up survey, intervention area club members reported that they conducted one to two visits per week to families affected by HIV and AIDS, with females caring for an average of approximately four HIV-positive clients and four OVC and males caring for an average of four HIV-positive clients and five OVC in the last three months. In the comparison area, youths reported caring for fewer than two HIVpositive clients and OVC.

\section{Male and female youth caregivers successfully provided a wide range of services but were unable to meet basic material needs.}

Youth caregivers reported that they were most able to provide help with cleaning, nursing care, counseling, and making clinic referrals, and clients reported satisfaction with these services. However, both youth caregivers and clients reported dissatisfaction with the youth's inability to meet material needs, including food, medicine, and transportation.

Contrary to early concerns that youths would only do tasks according to expected gender roles, researchers found that trained male and female caregivers provided similar kinds of care-giving services, including counseling and housework. Although same-sex caregivers were required for bathing, the only other activity in which a gender difference appeared was in contacting external organizations for assistance, which was reported by a greater proportion of males.

\section{OVC emerged as a key concern for adult clients and caregivers.}

The study originally focused on meeting the needs of adult clients, but trained youth caregivers soon began reporting that children in the homes they were visiting also required care and support. As a result, the intervention was expanded to include the specific needs of OVC. The youth caregivers were trained to involve OVC in recreational activities to reduce their sense of isolation, to contact schools to make sure that their needs are recognized, and to make referrals to NGOs working with OVC in cases when necessary.

\section{Caregivers and clients felt positive about the program.}

Male and female caregivers alike appear to have been well received by the clients; trained youth caregivers reported that, over time, clients grew friendlier and requested more visits. Reported increases in disclosure of HIV status to them by clients indicated a growing level of trust for the youth caregivers. Trained youth caregivers reported a number of benefits, including achieving satisfaction from serving their communities, gaining the respect of communities and leaders, increasing their own knowledge and skills, undertaking income-generating activities, and achieving a new status that permitted access to institutions and services. Some also said that the caregiving activities had provided them with the motivation to change their own sexual behavior. Despite the 
benefits of the program, youths said they experienced emotional distress when caring for clients and OVC with needs that were beyond their capabilities, such as dealing with rejection and family disputes, funeral arrangements, or severe food shortages.

\section{Youth in the intervention area increasingly believe that they are at risk of HIV infection.}

During the course of the study, youth in the intervention area became significantly more aware that they are potentially at risk of HIV infection. In the intervention area, the proportion of males who believed that they were not at risk of infection dropped sharply from 76 percent to 31 percent $(\mathrm{p}<$ $0.05)$, and from 89 percent to 41 percent among females $(\mathrm{p}<0.05)$. Smaller declines were apparent in the comparison area, where youth also received prevention training (males: 61 percent to 51 percent; females: 67 percent to 62 percent, NS). Discussion at the dissemination workshops revealed that the greater change in perception of risk in the intervention area could be attributed to respondents' enhanced awareness of the consequences of HIV through increased contact with clients, some of whom were close to their own age.

Perceptions of who is at risk of HIV infection changed in the intervention area, as youth increasingly recognized that females are more vulnerable (males: 61 percent to 74 percent, $\mathrm{p}<.05$; females: 50 percent to 69 percent, $\mathrm{p}<0.05$ ). There was no statistically significant change in the comparison area, although baseline levels were similar.

\section{Youth reported high levels of abstinence.}

Recent sexual activity among anti-AIDS club members was low, with high levels of reported abstinence (including secondary abstinence) among males and females. At the first round, 64 percent of males and 88 percent of females in the intervention area reported that they had not had sex during the three months preceding the survey, and this did not change significantly at the second round. Among respondents who said that they had had sex during this period, most of them (68 percent of males, 90 percent of females) claimed to have had only one partner, with no significant changes at follow-up. In the comparison area, 79 percent of males and 90 percent of females said that they had not had sex in the three months preceding the survey. Of those who had sex during this period, 74 percent of males and 100 percent of females reported that they had one partner.

\section{Peer pressure and gift giving influence risk behaviors.}

As with many young people, respondents in this study indicated that peer pressure is an important influence on risk behaviors, including alcohol and drug consumption and having a boyfriend or girlfriend. Both males and females mentioned the exchange of sex for gifts as an added pressure on young people, allowing them to acquire food or money for their family or luxuries (such as body lotion) for themselves. For example, in the first round, 6 percent of males and 16 percent of 


\section{Hgrizons}

females in the intervention area, and 11 percent of males and 13 percent of females in the comparison area had exchanged sex for gifts. Participants in the dissemination workshops corroborated the existence of sexual exchange by females and males, and cited examples of boys pressured into sex with older women, often businesswomen. They also felt that orphans might be particularly vulnerable to forced sex and highlighted the need to raise the issue of forced sex within the extended family.

\section{Reported condom use increased only among trained youth caregivers, although it was already high in both areas.}

Among the youths who reported that they had had sex, ever-use of condoms was similar between the two study areas at baseline, but increased significantly only in the intervention area: among males from 61 percent to 81 percent ( $\mathrm{p}<0.05$ ), and among females from 67 to 81 percent ( $\mathrm{p}<$ 0.05). Among those who reported that they had ever used a condom, reported condom use at last sex was high and changed little, fluctuating at around 80 to 90 percent of males and females.

Although the youths felt that their knowledge of condoms improved through the prevention training, and their motivation to protect themselves from HIV increased through the care and support activities, club members at the dissemination meetings revealed that condoms are still used inconsistently, reflecting respondents' limited ability to get condoms and some respondents' negative views of condoms within long-term relationships. These barriers call into question the accuracy of the high reported rates of condom use.

\section{Youth in the intervention area increasingly acknowledged joint responsibility for providing a condom.}

At baseline in the intervention area, 84 percent of males and 74 percent of females believed that supplying a condom should be the responsibility of males, and the frequency of this response dropped significantly by the second round (to 58 percent of males and 54 percent of females, both $\mathrm{p}<0.05)$ as youth recognized that condoms are a joint responsibility. Little change in this indicator was observed in the comparison area, where approximately 70 percent of all respondents at both survey rounds said that supplying a condom was a responsibility for males.

\section{Anti-AIDS club members report that they have changed their behavior.}

In both study areas, youth were asked whether they had changed their behavior since joining the anti-AIDS clubs. Youth in both intervention and comparison areas reported statistically significant increases in ever-use of condoms and restricting sexual activity to one partner. Although these data may not reflect the same trends as the indicators above, they may represent respondents' intentions to change and improved prevention awareness. In the intervention area, there was a significant increase (although overall levels were low) in males and females who reported asking their partner to be faithful, indicating enhanced partner communication, while youth in the comparison area 
remained virtually unchanged. At the dissemination workshops, the participants explained that being a member of an anti-AIDS club was a great motivation for behavior change, and that the behavior of club members was qualitatively very different from that of their non-club member peers.

\section{There was no change in stigmatizing attitudes among trained youth caregivers, who already felt positively toward people living with HIV and AIDS.}

Almost all indicators used for stigma showed high levels of acceptance of people living with HIV and AIDS by youth in both study areas and survey rounds, with no gender differences, and this was not increased or eroded at follow-up. Most youths said they would feel comfortable about shaking hands with, using the same plate as, or working with people living with HIV and AIDS. The only indicator that dropped significantly was whether people living with HIV and AIDS deserved compassion, which fell among youth in the comparison area only, from 79 percent to 67 percent ( $p$ $<0.05)$. In the intervention area, where youth had closer contact with people living with HIV and AIDS, 90 percent of youth felt that they deserved compassion, which was maintained at 91 percent at follow-up.

\section{Trained youth caregivers report a decrease in perceived community stigmatization of families affected by AIDS.}

In the first survey round, approximately one-fifth of youth in both study areas said that people living with HIV and AIDS are treated badly in the community. Examples cited in the dissemination workshops included verbal abuse, isolation, rejection, rumors, and gossip, which were felt to be worse in the villages than the semi-urban areas. Quantitatively, the figures did not change at the time of the second survey, although some clients and youth caregivers felt that the program was beginning to make a difference.

Our community is beginning to accept people living with HIV and AIDS since youth caregivers starting visiting; they are not as fearful as before. (Client, Kale Community)

We have noticed that family members are beginning to take more interest in caring for relatives with HIV/AIDS. (Youth caregiver, Mantumbusa Community Club)

When survey respondents were asked about families who have lost members to AIDS, there was a significant increase in the proportion of youth in the intervention area who felt they were treated the same as others by the community (64 percent to 78 percent; $p<0.05$ ). No similar improvement was recorded in the comparison area. This shift may be due to specific advocacy activities conducted by trained youth caregivers to encourage support of AIDS-affected families, as well as increased visibility of the program in the targeted communities (e.g., youth wore special aprons that identified the program) and involvement of village heads. 


\section{Hgrizons}

Headmen go ahead of time to inform the community of our care and support activities.

(Youth caregiver, Mutiti Basic School Club)

Our village head gives us protection and if a problem arises, he is there to solve it. (Youth caregiver, Kampampi Basic School Club)

\section{Mutually beneficial partnerships with local community groups and institutions provided crucial elements of support and reinforcement to the activities of the youth caregivers.}

Local partnerships helped to address challenges experienced by youth caregivers, and provided support in problem-solving and community mediation. They also enhanced the credibility of the youth caregivers in the community by providing increased acceptance and support, which in turn reinforced youth motivation for their new responsibilities.

\section{Conclusions and Lessons Learned}

Discussions with caregivers and clients demonstrated that trained youth are able to meet a range of client and OVC needs, to the satisfaction of their clients, and that their efforts may be laying the foundation for decreased isolation and stigmatization of AIDS-affected families. The findings of this study suggest one way in which youth can be empowered to confront the realities of HIV in their own lives and their communities, and to confront the accompanying barriers of stigma, denial, and ignorance, while simultaneously serving as a resource to people in their communities who are living with HIV and AIDS.

This study also demonstrated that NGOs and youth clubs working in relatively isolated rural and semi-urban areas can meet with positive and enthusiastic responses and high levels of participation. Providers seeking to replicate or scale-up this process should be sure to recognize the lessons learned from the implementation of this intervention, including the importance of involving community leaders and institutions, clear communication of the range of needs to be served by caregivers, and the need for ongoing monitoring and support for youth caregivers.

\section{Next Steps}

Horizons and partners are implementing an 18-month program to mobilize local resources and promote local management. The goal is to complete the transfer of program ownership to the community in order to sustain youth involvement in care and support activities. A particular focus of the continuing study is to further strengthen local partnerships and expand network linkages in order to promote community ownership and sustainability. 


\section{Introduction}

\section{HIV and AI DS in Zambia}

According to recent Demographic and Health Survey (DHS) data, adult HIV prevalence in Zambia is 18 percent among females and 13 percent among males (age 15 to 49). Among young people age 15 to 19 , female prevalence is 6.6 percent and is 1.9 percent among males. HIV prevalence is generally more than twice as high in urban areas generally as in rural areas: 23 percent and 11 percent, respectively. Areas particularly hard hit by HIV include the more urban areas of Lusaka and the Copperbelt region, but even the more rural areas are beginning to provide evidence for the rapid spread of HIV and AIDS. Recent DHS data for Luapula and Northern provinces, located 700 to 1,000 kilometers from Lusaka, indicates HIV prevalence of 10 to 13 percent among women and 6 to 9 percent among men (Zambia DHS 2003).

Although a national survey of sexual behavior provides some evidence to suggest that high-risk sexual practices are on the decline (Zambia Central Board of Health et al. 2000), Zambia continues to bear a high burden of HIV infection. During 2001, there were an estimated 120,000 deaths attributable to AIDS-related illness, and an estimated 1,200,000 adults and children were living with HIV at the end of 2001 (UNAIDS et al. 2002).

\section{Care and Support in Zambia}

The multiple care and support needs of people living with HIV and AIDS vary according to many factors, including stage of illness, personal responsibilities, number of dependents, residential location, socioeconomic status, level of stigma in community, and availability of health services. Their needs include assistance with such domestic chores as cooking, cleaning, laundry, and fetching water or firewood, and with such personal tasks as bathing, dressing wounds, help with exercise, and help with transport to health clinics.

A recent national survey indicated that fears of stigma are apparent in Zambia: 38 percent of men and 39 percent of women said that if a family member were HIV-infected, they would want to keep it a secret. Furthermore, willingness to care for a family member with HIV was high in all areas, especially among urban respondents (Zambia Central Board of Health 2000). Thus, most of the burden of care for people living with HIV and AIDS falls to household and family members.

To support household and family members, communities are seeking new ways of responding to the needs of people who are HIV-positive, their households, and their dependents. A Situation Analysis exploring how HIV and AIDS affect women in urban and rural Zambia (Ndola and Kaoma districts) revealed that although women and girls provide most caregiving, they are poorly equipped to carry out this responsibility, due to their limited earning capacity and low social and educational status. A cross-sectional survey revealed that one quarter of the 997 women interviewed knew of someone living with AIDS, and 62 percent knew someone who had died of 


\section{Hgrizons}

AIDS. Thirteen percent were currently caring for or had cared for someone with AIDS, and 21 percent of women knew of someone giving care. The most commonly mentioned sources of external support for people living with HIV and AIDS and caregivers were the family and the Church, but focus group discussions revealed that different actors, including workplaces, government bodies and NGOs also have roles to play in providing physical and emotional support (Macwan'gi, Sichone, and Kamanga 1994).

\section{Youth Anti-AI DS Activities}

Youth programs in Zambia have to date mainly focused on HIV prevention, often through the mechanism of anti-AIDS clubs in schools and communities. Anecdotal reports suggest that although knowledge and awareness of HIV and AIDS prevention are generally high among young people in Zambia (and particularly among members of anti-AIDS clubs), this is not necessarily reflected in their behavior or in their perception of risk. All schools in Zambia, from primary through secondary school, are required to form anti-AIDS clubs to give students the opportunity for involvement in HIV prevention education and related activities. School students join these clubs voluntarily, in order to learn more about HIV and AIDS and in turn to educate their peers, often motivated by seeing the effects of the epidemic in their own communities. Community anti-AIDS clubs represent a more diverse group of youth and address a broader range of social needs, including income generation. Club members act as role models and peer educators within their school or community. Clubs are led by patrons and matrons, who may be school teachers, clinic officers, or community leaders.

Findings from formative research conducted as part of this study revealed that a common motivation for joining the clubs was that youth had seen many AIDS-related deaths in their community, and wanted to be informed so as to help others and take responsibility for themselves. Both school and community clubs conduct recreational and HIV/AIDS activities, including football and netball games, drama, "red ribbon" HIV awareness campaigns, and distribution of information and condoms. However, there has been little work to date by anti-AIDS clubs on addressing the care and support needs of people living with HIV and AIDS in their communities.

Given the likelihood that many members are also helping to care for sick relatives without adequate training and support, building the capacity of young people to be a resource for their families and communities is a logical extension of the work of anti-AIDS clubs. In addition to providing care and support, fostering greater interaction between youth and people living with HIV and AIDS may also reinforce educational messages and help motivate young people to protect themselves from HIV infection. The impact of care and support training and involvement on the HIV risk behavior of these young people has not previously been studied. 


\section{Background}

\section{Aims of the Study}

Horizons, in collaboration with CARE International and Family Health Trust, undertook a quasiexperimental intervention study to examine the potential of trained members of anti-AIDS clubs to contribute to care, support, and stigma-reduction activities, and to determine the impact of their involvement in these activities on their HIV-related beliefs and behaviors. Specifically, the study aimed to:

- Identify which care and support needs of HIV-affected individuals and their families can be met by trained youth.

- Determine whether youth engaged in care and support activities contribute to reducing household- and community-level stigma.

- Identify ways to develop and sustain local capacity for involving youth in community care and support efforts.

- Determine whether the involvement of youth in care and support activities decreases the probability that they will engage in risk behaviors (See Figure 1 for linkages)

Figure 1 Hypothesized linkages between caregiving and behavior change

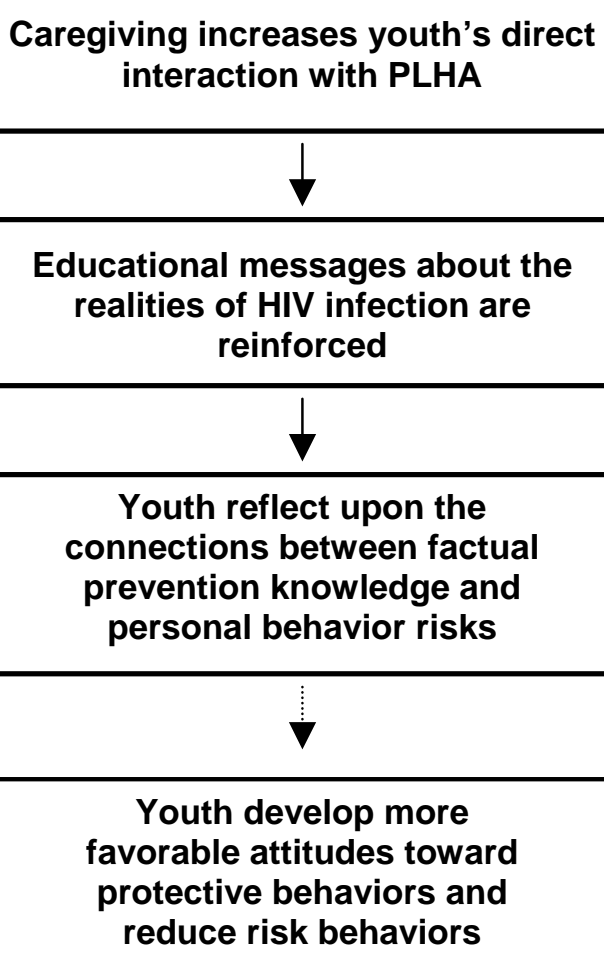




\section{Hgrizons}

\section{Study Setting}

The study was conducted in semi-urban and rural communities in Luapula and Northern provinces. Thirty clubs in Mansa and Nchelenge districts in Luapula Province served as intervention sites; an equal number in Mporokoso and Kasama districts in Northern Province served as comparison sites. Zambia DHS data indicate that Luapula and Northern provinces in general can be considered broadly similar with respect to population structure, socioeconomic activities, and HIV prevalence. However, HIV prevalence is suspected to be slightly higher in the Nchelenge District of Luapula, where population mobility is high due to the fishing trade.

Despite increasing reports of HIV and AIDS in the community, few organized community care and support activities existed in the study areas. One of the few local resources was a home-based care program under the auspices of the Catholic Diocese in Mansa District, which began training adult caregivers in Luapula Province in 2000.

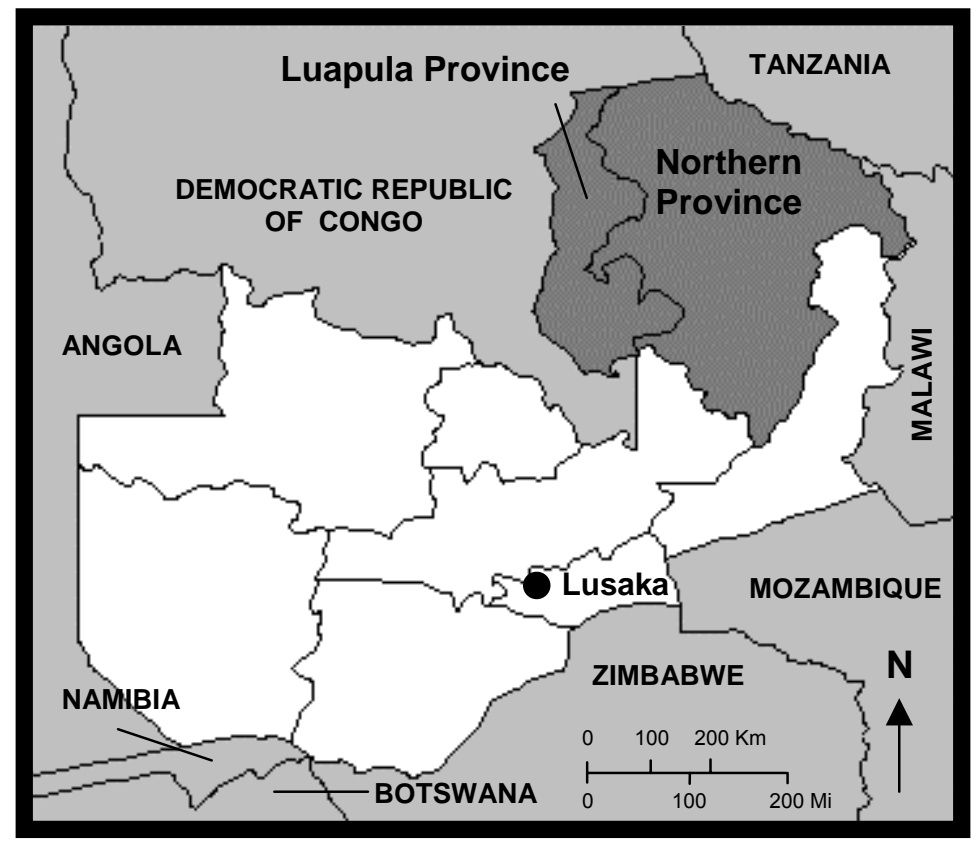

ZAMBIA 


\section{Study Design}

The study began with a formative research phase in March 2000 that was conducted in Luapula and Northern provinces with anti-AIDS club members (age 13 to 24) and community members. The researchers used participatory methods (e.g., pair-wise ranking, body maps, secret ballots, picture stories, casual flow diagrams) and focus group discussions with young people and community stakeholders.

Following the formative research phase, which revealed widespread support for youth involvement in care and support, 30 anti-AIDS clubs in Luapula Province (intervention area) and 30 anti-AIDS clubs in Northern Province (comparison area) were identified from among existing school and community clubs in rural and urban areas. Members of all 60 clubs received basic training in club management and HIV prevention using an adaptation of a curriculum developed by Family Health Trust, as well as materials for recreational activities (e.g., footballs, netballs, drums). Key topics addressed by the HIV prevention syllabus included local beliefs and practices, gender roles and relationships, and stigma. The club management training included aspects of leadership, membership recruitment and motivation, how to hold meetings, and how to write meeting minutes.

Members of the 30 intervention clubs in Luapula also received training in care and support; in how to network with existing resources and services, such as NGOs, OVC programs, clinics, and homebased care (HBC) teams; and in how to conduct stigma reduction activities. Care and support activities were not actively encouraged or supported in Northern Province. Table 1 summarizes the club activities in each of the study areas.

\section{Table 1 Club activities in the intervention and comparison areas}

\begin{tabular}{lcc}
\hline Club management training & $\begin{array}{c}\text { Intervention } \\
\text { Luapula Province }\end{array}$ & $\begin{array}{c}\text { Comparison } \\
\text { Northern Province }\end{array}$ \\
$\begin{array}{l}\text { HIV prevention training and material support } \\
\text { (e.g., educational and recreational materials, } \\
\text { condoms) }\end{array}$ & $\checkmark$ & $\checkmark$ \\
Care and support training and provision of kits & $\checkmark$ \\
$\begin{array}{l}\text { Networking and building partnerships with } \\
\text { community care and support resources }\end{array}$ & $\checkmark$ \\
$\begin{array}{l}\text { Advocacy activities to reduce stigma and } \\
\text { promote acceptance of youth caregivers }\end{array}$ & & $\checkmark$
\end{tabular}

To assess outcomes, research staff conducted semi-structured interviews at baseline with a crosssectional sample of club members from 16 of the 30 clubs in each area, chosen at random. These 


\section{Hgrizons}

data were compared to data collected from a follow-up interview with a different cross-sectional sample of club members from the same 16 clubs in each area selected at baseline.

\section{Data Collection and Analysis}

Baseline data collection took place in March 2001, after the HIV prevention and club management workshops were carried out among all 60 clubs in the intervention and comparison areas (Table 2). The follow-up survey was conducted in September 2002, approximately a year after the care and support training for the 30 clubs in Luapula, the intervention area, was carried out. During each of the surveys, data were collected over a two-week period. Questionnaires were field-tested several times before use. The sexual behavior and HIV risk questions used were the same at baseline and follow-up, while the care and support section of the questionnaire was expanded considerably from the baseline version at follow-up, in order to examine the new youth care and support activities in greater detail.

During baseline data collection, there was concern about the low number of female club members, and efforts were made to interview more females to reach the desired sample size of 458 each for intervention and comparison groups. It is possible that this may have slightly biased the sample, although it is unclear whether or how this has affected the results.

Qualitative data were also collected throughout the study and managed manually by CARE. Researchers held focus group discussions and in-depth interviews with caregivers, club patrons and matrons. People living with HIV and AIDS and their family members were also surveyed for their opinions of the youth caregivers.

Quantitative data were entered using Epi-Info and Epi-Data software. Data were imported into SPSS for analysis. Unless otherwise indicated, Pearson's chi-square test of independence was used to determine significance. Results are considered statistically significant at or below the 0.05 level, and this is indicated by an asterisk (*). Where significance of a comparison between the two rounds of data is not indicated, this is because the questions differed between the two survey rounds. For example, at baseline club members were asked whether they provided care to someone with a chronic illness - a commonly used euphemism for HIV and AIDS - which changed at follow-up to whether they cared for someone living with HIV/AIDS, a transition that reflects respondents' improved awareness. Only respondents age 13 to 25 were included in the analysis. Interviewers were recruited from the local area and trained in the survey methodology.

As findings emerged, participatory dissemination workshops with the anti-AIDS clubs and stakeholder meetings were conducted in the four districts in order to shed light on the results. 


\section{Table 2 Study activities}

\begin{tabular}{ll}
\hline March 2000 & $\begin{array}{l}\text { Formative research } \\
\text { HIV prevention and club management training }\end{array}$ \\
\hline March 2001 & $\begin{array}{l}\text { Commencement of care and support curriculum development with youths } \\
\text { and stakeholders } \\
\text { Baseline data collection }\end{array}$ \\
\hline August 2001 & Training of 12 local health professionals as trainers \\
\hline September 2001 & $\begin{array}{l}\text { Training of 300 youth caregivers from 30 clubs and providing kits } \\
\text { Field component: opportunity to visit clinics, VCT centers, and HBC } \\
\text { programs }\end{array}$ \\
\hline November 2001 & $\begin{array}{l}\text { Follow-on training to ensure that every club member had the opportunity to } \\
\text { be fully trained } \\
\text { Start of ongoing training sessions to address specific needs and concerns } \\
\text { raised by caregivers during the course of their work. }\end{array}$ \\
\hline September 2002 & Follow-up data collection \\
\hline July 2003 & Local dissemination workshops with stakeholders and youth club members \\
\hline
\end{tabular}

\section{Description of the Care and Support I ntervention}

The care and support training curriculum for youth and trainers was generated from formative research and adapted to local needs and the specific needs of young people. Formative research findings revealed that young people from school and community-based anti-AIDS clubs were enthusiastic about receiving formal training in care and support for people living with HIV and AIDS, and were eager to volunteer their participation in this initiative. Discussions with stakeholders and community members indicated broad support for the idea, although they also revealed gender and cultural concerns. Local residents explained that certain activities were seen as predominantly female tasks, including fetching water, cooking, and cleaning. Activities perceived as more suited to male caregivers included liaising with clinics and schools and counseling people about behavior change. Reservations were also expressed about the appropriateness of young people reaching out to provide care to older people living with HIV. Youths voiced concern about whether their churches would endorse their participation and whether their parents would approve of these activities, especially if they took time away from other gainful activities. Local stakeholders, including club patrons, clinic officers, and HBC program staff, also reported that levels of ignorance, misconceptions, and stigma surrounding HIV and AIDS was high among community members.

The first stage of the training process to better equip youth to provide care and support was the participatory development of a curriculum with youth and stakeholders in March 2001 (Box 1). The resulting curriculum covered a wide variety of topics, including HIV voluntary counseling and testing (VCT), stigma reduction, community- and home-based care, needs of OVC, children's 


\section{Hgrizons}

rights, and monitoring and reporting of care activities. During the caregiver training sessions,

trainers were careful to highlight for discussion the gender and cultural issues surrounding caregiving and HIV prevention that were raised during formative research, and how to handle these issues in a culturally sensitive way.

\section{Box 1 Training curriculum modules}

Module 1: Facts About HIV and AIDS

Module 2: HIV and AIDS-related Symptoms and Conditions

Module 3: HIV and AIDS Counseling, Testing, and Referral

Module 4: Community and Home-based Care and Support

Module 5: Care and Support of Orphans and Vulnerable Children

Module 6: Community Mobilization for Care and Support and Stigma Reduction

Module 7: Implementing and Monitoring Youth Care and Support Activities

During August 2001, 12 local health professionals received training in how to train anti-AIDS club members to provide care and support to clients using the curriculum. In September 2001, the youth training intervention commenced in earnest, covering 300 club members from 30 clubs in Luapula province. Training sessions included role-plays, presentations, discussion, life testimonies from people living with HIV and AIDS, and sharing of personal experiences of providing care.

At the start of the training, all clubs in the intervention province received a care kit containing items to help the caregivers treat sores and prevent infections (gloves, disinfectant, soap, cotton wool, gentian violet, bandages), document their experiences and collect data (pens and notebooks), and reinforce their group identity as youth caregivers (bags, aprons, and badges). These care kits were replenished every three months to enhance motivation among caregivers. Clubs also received two bicycles for use by caregivers, to facilitate regular visits to clients and to help them convey clients to clinics. One key component of the training was a field activity enabling club members to gain first-hand knowledge of clinics, VCT centers, and an HBC program, in order to introduce their services and build rapport with health workers and inform their interactions with clients receiving their services.

After two months, a session of follow-on training was conducted, during which the original training course was repeated to ensure that every club member had had the opportunity to receive training. Ongoing training and supervision sessions throughout the study gave the caregivers the opportunity to reflect on their role, and for trainers to address specific needs and concerns raised during the course of caregiving. These concerns included requests for more information about a variety of subjects, including nutrition, how to prevent TB infection, counseling, and conflict resolution for families in difficult situations. 


\section{Community Participation}

The nature of the program required the involvement of a wide range of stakeholders. A local advisory group was established to give inputs into the program design and management, and to advocate for community support. Members included representatives of the AIDS Task Force, the Ministry of Education, the Ministry of Community Development, Ministry of Health, NGOs, community leaders, local churches, and the Catholic Diocese.

Right from the early stages of the study, researchers recognized the advantages of collaboration with local partners. Program staff worked with stakeholders to promote active collaboration between trained youth caregivers and local institutions, including health centers, adult home-based care teams, community leaders, and NGOs.

Partnership with the Catholic Diocese home-based care program was of particular importance in the development of the youth care and support training. Adults trained in providing home-based care by the Catholic Diocese of Mansa worked closely with youth, providing them with on-site supervision, skills training, psychosocial support, and mentoring. In Nchelenge, where the Diocese did not have a program, the District AIDS Task Force provided support to youth caregivers.

One of the key areas in which community support became essential was in the initial identification of clients who might appreciate the services of youth caregivers. The first referrals to the program came from the youth club members themselves, based on their knowledge of relatives and neighbors with chronic illness (a commonly used euphemism for suspected HIV or AIDS). As the study progressed and youth caregivers became more trusted, health providers, community members, and elders began to refer other people living with HIV and AIDS to the program.

\section{Study Limitations}

The quasi-experimental study design implies a number of limitations. For ethical reasons, the intervention could not be compared to a strict control group receiving no services. Instead, the care and support training was measured against a comparison group receiving a basic package of training in HIV prevention and club management. The use of a randomized design was not feasible due to the risks of contamination (spillover of interventions between members and between clubs) and the cost of following-up individuals.

As part of the training, club members received very strong HIV prevention and education messages. Thus, the possibility remains that their answers to questions about risk behaviors were biased toward what they thought would be the "correct" answer. 


\section{Hgrizons}

\section{Results}

\section{Profile of Respondents}

The age range of survey respondents analyzed was from 13 to 25 years, almost all of whom were single (Table 3). The two surveys were cross-sectional, separated by a period of 18 months. During this period, some new club members joined and some former members graduated from school and left club activities. The cross-sectional samples remain broadly comparable between both rounds. Community clubs were more stable in their membership than school-based clubs.

Club members include youth who are themselves orphaned or living in households possibly affected by HIV and AIDS, as evidenced by the fact that only about half of the sample at both rounds lived with both parents.

In Northern Province, nearly 50 percent of the respondents identified themselves as Catholic, compared with Luapula, where other denominations, including Seventh Day Adventists, Watchtower, United Church of Zambia, and Christian Missions in Many Lands, were more predominant. The Catholic Church has a much higher presence in the organization of local AIDS activities than other denominations.

By the second survey round, respondents in the intervention province were more likely to have been club members for a period of at least 18 months than their counterparts in the comparison group (Luapula males: 49.8 percent; Northern males 32.5 percent; $p<0.05$; Luapula females: 35.6 percent; Northern females: 23.9 percent; $p<0.05)$. This implies that the intervention was associated with a higher retention rate of club members, who remained involved with club activities for a longer time period. 
Table 3 Respondent sociodemographic profile (distributions in percent)

\begin{tabular}{|c|c|c|c|c|c|c|c|c|}
\hline & \multicolumn{4}{|c|}{ Males } & \multicolumn{4}{|c|}{ Females } \\
\hline & \multicolumn{2}{|c|}{$\begin{array}{l}\text { Intervention } \\
\text { Luapula }\end{array}$} & \multicolumn{2}{|c|}{$\begin{array}{l}\text { Comparison } \\
\text { Northern }\end{array}$} & \multicolumn{2}{|c|}{$\begin{array}{l}\text { Intervention } \\
\text { Luapula }\end{array}$} & \multicolumn{2}{|c|}{$\begin{array}{l}\text { Comparison } \\
\text { Northern }\end{array}$} \\
\hline & $\begin{array}{c}R 1 \\
n=200\end{array}$ & $\begin{array}{c}R 2 \\
n=280\end{array}$ & $\begin{array}{c}R 1 \\
n=209\end{array}$ & $\begin{array}{c}R 2 \\
n=269\end{array}$ & $\begin{array}{c}R 1 \\
n=165\end{array}$ & $\begin{array}{c}R 2 \\
\mathrm{n}=216\end{array}$ & $\begin{array}{c}R 1 \\
n=222\end{array}$ & $\begin{array}{c}\mathrm{R} 2 \\
\mathrm{n}=218\end{array}$ \\
\hline $\begin{array}{l}\text { Mean age } \\
\text { (years) }^{\mathrm{a}}\end{array}$ & 18.0 & $18.7^{*}$ & 17.7 & 17.8 & 16.2 & $\overline{16.7}$ & 16.5 & 16.2 \\
\hline \multicolumn{9}{|l|}{$\begin{array}{l}\text { Religious } \\
\text { denomination }\end{array}$} \\
\hline Catholic & 29 & 27 & 46 & 41 & 26 & 29 & 44 & $33^{*}$ \\
\hline Other & 71 & 75 & 54 & 59 & 73 & 72 & 49 & $66^{*}$ \\
\hline None & 1 & 0 & 1 & 0 & 0 & 0 & 0 & $1^{*}$ \\
\hline $\begin{array}{l}\text { Currently in } \\
\text { school }\end{array}$ & 75 & 73 & 85 & 81 & 90 & 90 & 92 & 90 \\
\hline Single & 94 & 90 & 97 & 92 & 99 & 97 & 98 & 95 \\
\hline $\begin{array}{l}\text { Living with } \\
\text { both parents }\end{array}$ & 49 & $36^{*}$ & 43 & $31^{*}$ & 52 & 50 & 56 & $40^{*}$ \\
\hline
\end{tabular}

\section{Involvement in HIV Prevention Activities}

Clubs in both intervention and comparison areas were encouraged and given support to conduct HIV prevention activities for members and outreach activities for non-club members, including educational dramas and condom distribution. Table 4 indicates that at baseline, reported youth involvement in these different types of activities was similar between intervention and comparison areas. Community outreach activities included one-on-one and group discussions, while lectures referred mainly to activities conducted within clubs or in school settings. By the second survey round, reported involvement in all types of activities had increased significantly among both males and females in the intervention area. In the comparison area, involvement had increased somewhat in a few selected activities (males: distribution of materials and condoms; females: lectures) but to a lesser extent. 
Table 4 Reported involvement with prevention activities in last 3 months (mean frequency) $)^{a}$

\begin{tabular}{|c|c|c|c|c|c|c|c|c|}
\hline \multirow[b]{3}{*}{ Activity type } & \multicolumn{4}{|c|}{ Males } & \multicolumn{4}{|c|}{ Females } \\
\hline & \multicolumn{2}{|c|}{$\begin{array}{l}\text { Intervention } \\
\text { Luapula }\end{array}$} & \multicolumn{2}{|c|}{$\begin{array}{l}\text { Comparison } \\
\text { Northern }\end{array}$} & \multicolumn{2}{|c|}{$\begin{array}{l}\text { Intervention } \\
\text { Luapula }\end{array}$} & \multicolumn{2}{|c|}{$\begin{array}{c}\text { Comparison } \\
\text { Northern }\end{array}$} \\
\hline & $\begin{array}{c}R 1 \\
n=200\end{array}$ & $\begin{array}{c}R 2 \\
n=280\end{array}$ & $\begin{array}{c}R 1 \\
n=209\end{array}$ & $\begin{array}{c}R 2 \\
n=269\end{array}$ & $\begin{array}{c}R 1 \\
n=165\end{array}$ & $\begin{array}{c}R 2 \\
n=216\end{array}$ & $\begin{array}{c}R 1 \\
n=222\end{array}$ & $\begin{array}{c}R 2 \\
n=218\end{array}$ \\
\hline $\begin{array}{l}\text { Peer } \\
\text { education }\end{array}$ & 3.49 & $5.14^{*}$ & 3.09 & 2.75 & 2.13 & $4.09^{*}$ & 2.52 & 2.01 \\
\hline $\begin{array}{l}\text { Drama and } \\
\text { role plays }\end{array}$ & 2.80 & $4.48^{*}$ & 3.11 & 3.44 & 1.71 & $3.06^{*}$ & 2.06 & 1.62 \\
\hline $\begin{array}{l}\text { Distributing } \\
\text { educational } \\
\text { materials }\end{array}$ & 0.54 & $3.64^{*}$ & 0.76 & $1.18^{*}$ & 0.52 & $2.04^{*}$ & 0.70 & 0.73 \\
\hline $\begin{array}{l}\text { Distributing } \\
\text { condoms }\end{array}$ & 0.81 & $8.89^{*}$ & 0.69 & $2.72^{*}$ & 0.58 & $5.32^{*}$ & 0.60 & 0.80 \\
\hline $\begin{array}{l}\text { Community } \\
\text { outreach }\end{array}$ & 1.99 & $6.77^{*}$ & 1.76 & 2.28 & 1.09 & $5.92^{*}$ & 1.13 & 0.88 \\
\hline $\begin{array}{l}\text { Red ribbon } \\
\text { campaign }\end{array}$ & 1.52 & $3.31^{*}$ & 1.85 & 2.10 & 1.24 & $2.64^{*}$ & 1.11 & 1.99 \\
\hline Lectures & 0.98 & $3.58^{*}$ & 1.82 & 1.87 & 0.93 & $2.14^{*}$ & 1.80 & $1.05^{\star}$ \\
\hline
\end{tabular}

HIV prevention activities in both intervention and comparison areas emphasized the importance of determining one's HIV status by using local VCT services. Researchers asked club members if they had ever used VCT services themselves, or if they had recommended the services to others, including their peers and family members. Table 5 indicates that there were statistically significant increases in personal uptake of VCT among females in the comparison area, and in referral of the services to others among males in the intervention area. 
Table 5 VCT attendance and referrals

\begin{tabular}{|c|c|c|c|c|c|c|c|c|}
\hline & \multicolumn{4}{|c|}{ Males } & \multicolumn{4}{|c|}{ Females } \\
\hline & \multicolumn{2}{|c|}{$\begin{array}{l}\text { Intervention } \\
\text { Luapula }\end{array}$} & \multicolumn{2}{|c|}{$\begin{array}{l}\text { Comparison } \\
\text { Northern }\end{array}$} & \multicolumn{2}{|c|}{$\begin{array}{l}\text { Intervention } \\
\text { Luapula }\end{array}$} & \multicolumn{2}{|c|}{$\begin{array}{c}\text { Comparison } \\
\text { Northern }\end{array}$} \\
\hline & $\begin{array}{c}\text { Round } 1 \\
n=200\end{array}$ & $\begin{array}{c}\text { Round } 2 \\
n=280\end{array}$ & $\begin{array}{c}\text { Round } 1 \\
n=209\end{array}$ & $\begin{array}{c}\text { Round } 2 \\
n=269\end{array}$ & $\begin{array}{l}\text { Round } 1 \\
n=165\end{array}$ & $\begin{array}{c}\text { Round } 2 \\
n=216\end{array}$ & $\begin{array}{l}\text { Round } 1 \\
n=222\end{array}$ & $\begin{array}{c}\text { Round } 2 \\
n=218\end{array}$ \\
\hline $\begin{array}{l}\text { Been to a } \\
\text { counseling } \\
\text { center and tested }\end{array}$ & 16 & 18 & 9 & 14 & 8 & 7 & 4 & $10^{*}$ \\
\hline $\begin{array}{l}\text { Referred } \\
\text { someone else for } \\
\text { VCT }\end{array}$ & 33 & $51^{*}$ & 28 & 34 & 25 & 30 & 20 & 20 \\
\hline
\end{tabular}

${ }^{*} p \leq 0.05$

Youth in both areas were encouraged to discuss topics related to HIV with their fellow club members and their peers outside the clubs. During the surveys, they were asked whether they had engaged in discussions on the topics of delaying sex (primary abstinence), stopping sexual activity (secondary abstinence), obtaining treatment for STIs, and getting and using condoms (Figure 2). In the intervention area, discussion of condoms and STI treatment increased significantly between rounds among both males and females, to levels much higher than the comparison area.

(Discussions of primary and secondary abstinence also increased in the intervention area, but these had been lower than the comparison area prior to the training.) These increases were likely associated with the emphasis on outreach activities with non-club members in clubs in the intervention area, where youth received additional encouragement. Furthermore, as a result of their care activities, youth in the intervention area had more opportunities to engage in discussions with clients for whom they were caring, their family members and other community members. 
Figure 2 Outreach activities-youths who said that they discussed HIVrelated topics with club non-members

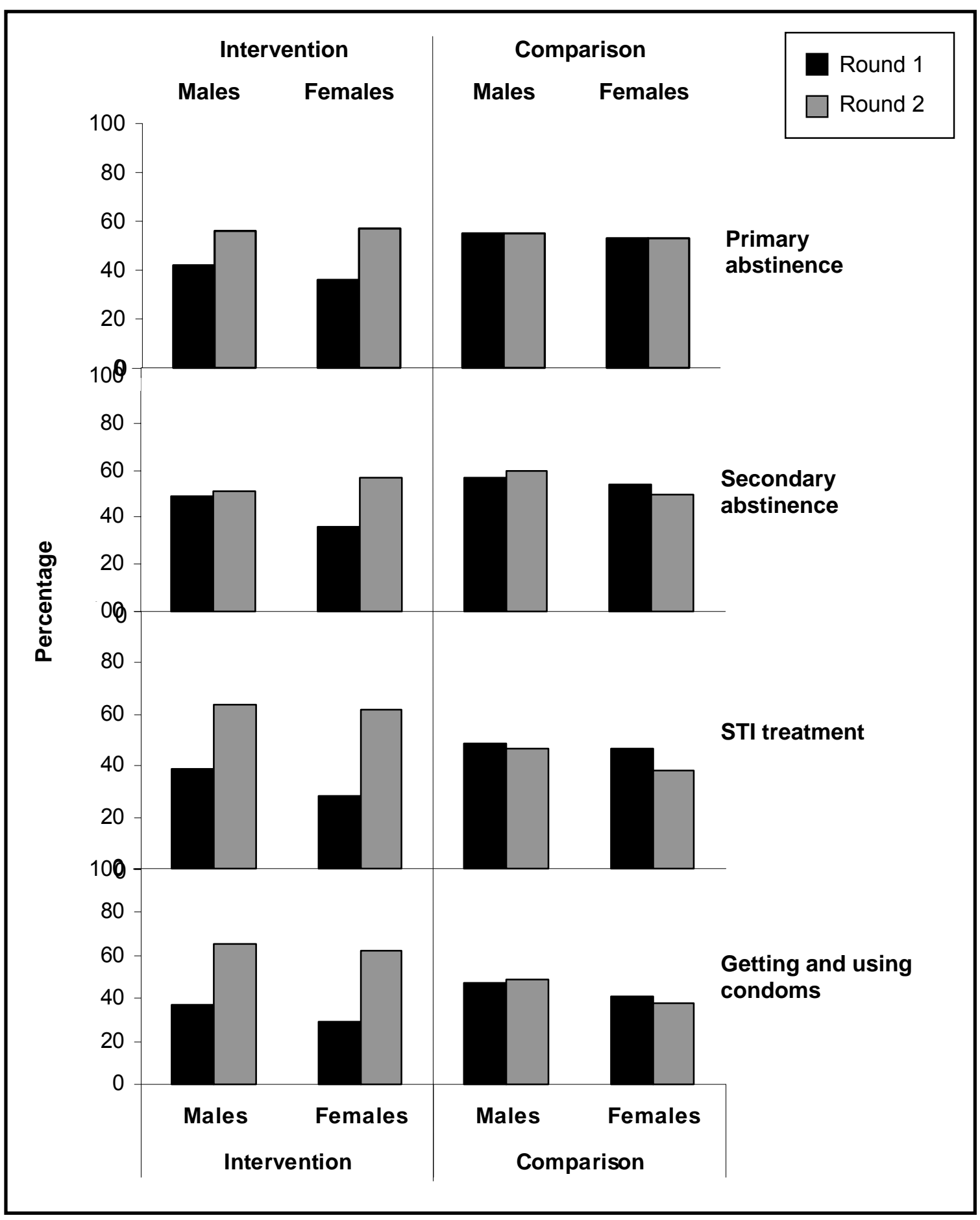




\section{I nvolvement in HIV Caregiving Activities}

Although formative research indicated that the club members were enthusiastic about being trained as youth caregivers, youth highlighted cultural concerns about the suitability of young people, and especially boys, for some of the tasks under discussion. During the caregiver training sessions, trainers were careful to highlight these issues for discussion and to provide appropriate support to male and female youth.

Before the care and support training intervention, caregiving activities were similar between males and females in Luapula and Northern provinces: approximately half of all club members reported that they had provided care to a family or community member with a chronic illness (a commonly used euphemism for suspected HIV or AIDS) during the preceding six months. Because of the changes in question wording (from chronic illness to HIV), precise significance values have not been calculated. Figure 3 indicates that while caregiving activities increased among all groups, the most striking changes were observed among youth in the intervention area, where youth had been receiving training and support to enhance their caregiving.

\section{Figure 3 Provided care during last 6 months}

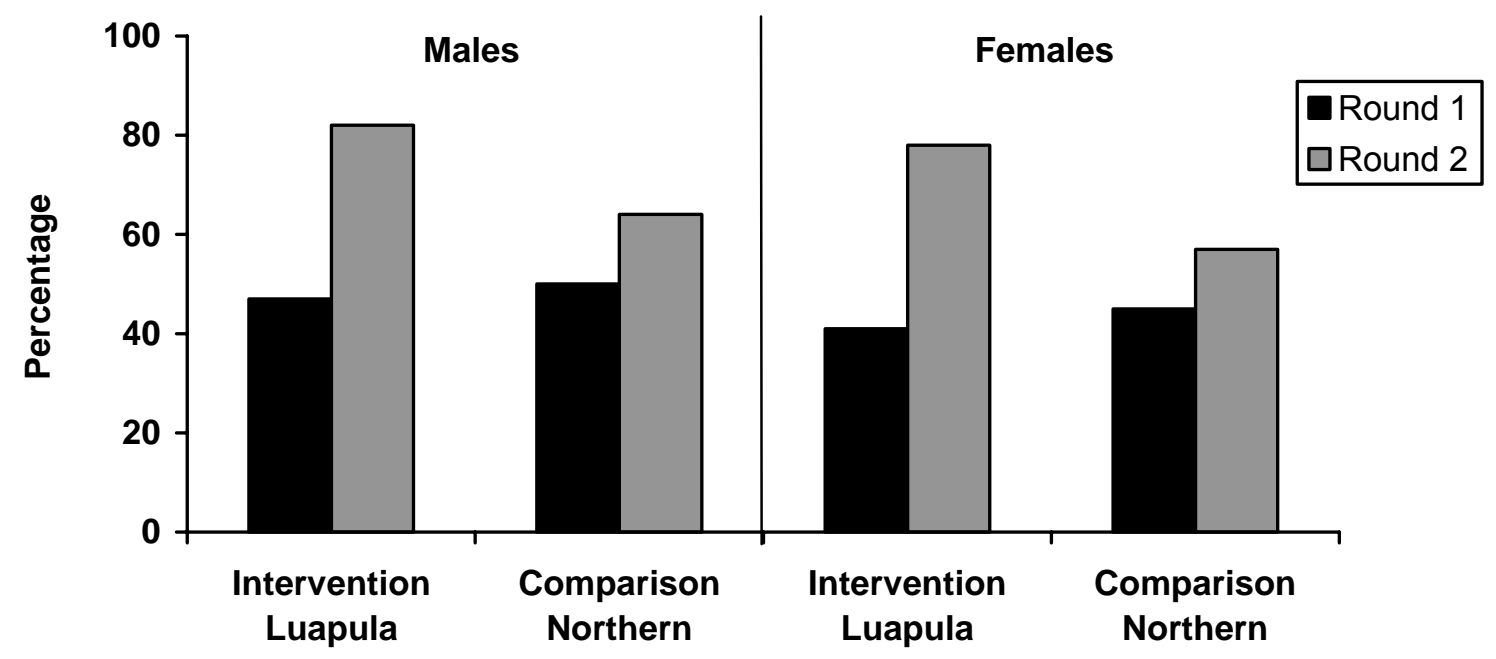

By the follow-up survey, club members in the intervention area reported that they conducted one to two visits per week to families affected by HIV and AIDS. Youth in Luapula reported caring for 3.8-4.0 HIV-affected individuals and 4.0-4.7 orphans and vulnerable children during the preceding three months. In the comparison area, where caregiving activities were not actively supported, youths reported caring for fewer clients and OVC (Figure 4). 
Figure 4 Mean number of clients and OVC cared for in last 3 months at round 2

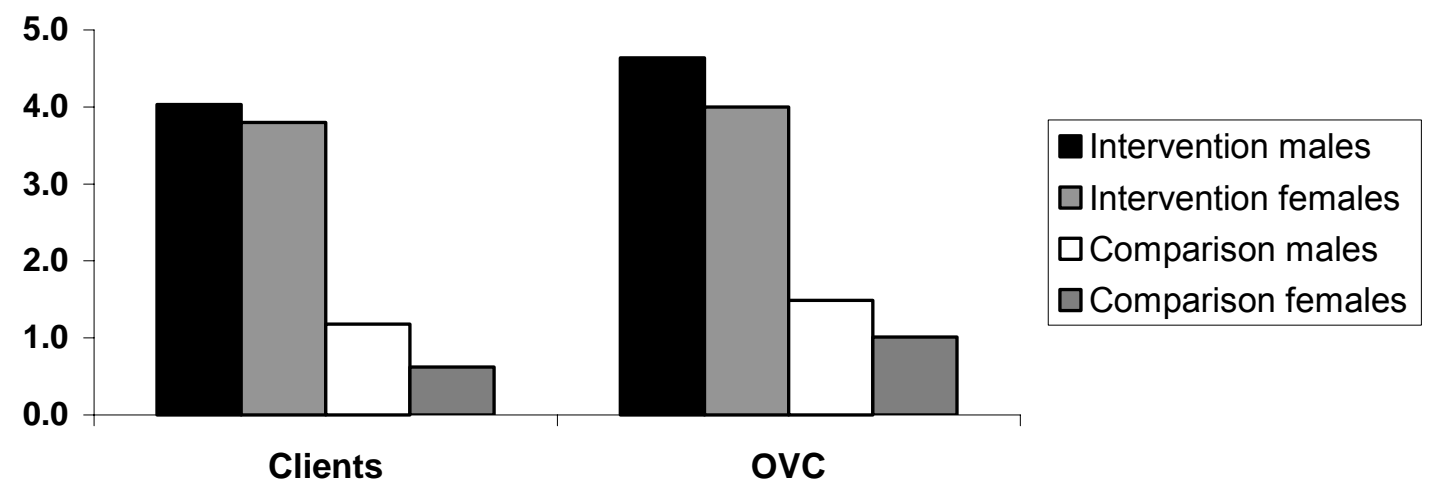

Youth in the intervention area receiving training in care and support reported that they had become more comfortable dealing with people living with HIV and AIDS, compared to untrained youth where little change was documented (Figure 5). During the dissemination of baseline results, some youths said that although youths felt generally comfortable caring for people living with HIV and AIDS, this might not hold once they were actually giving care, especially to those infected with tuberculosis. However, by the next round of dissemination workshops after the follow-up surveys, this concern was found to be overestimated: youths felt that the care and support training and the care kits equipped club members with the necessary skills and materials for giving care without placing oneself at risk.

Figure 5 Reported comfort level with people living with HIV and AIDS

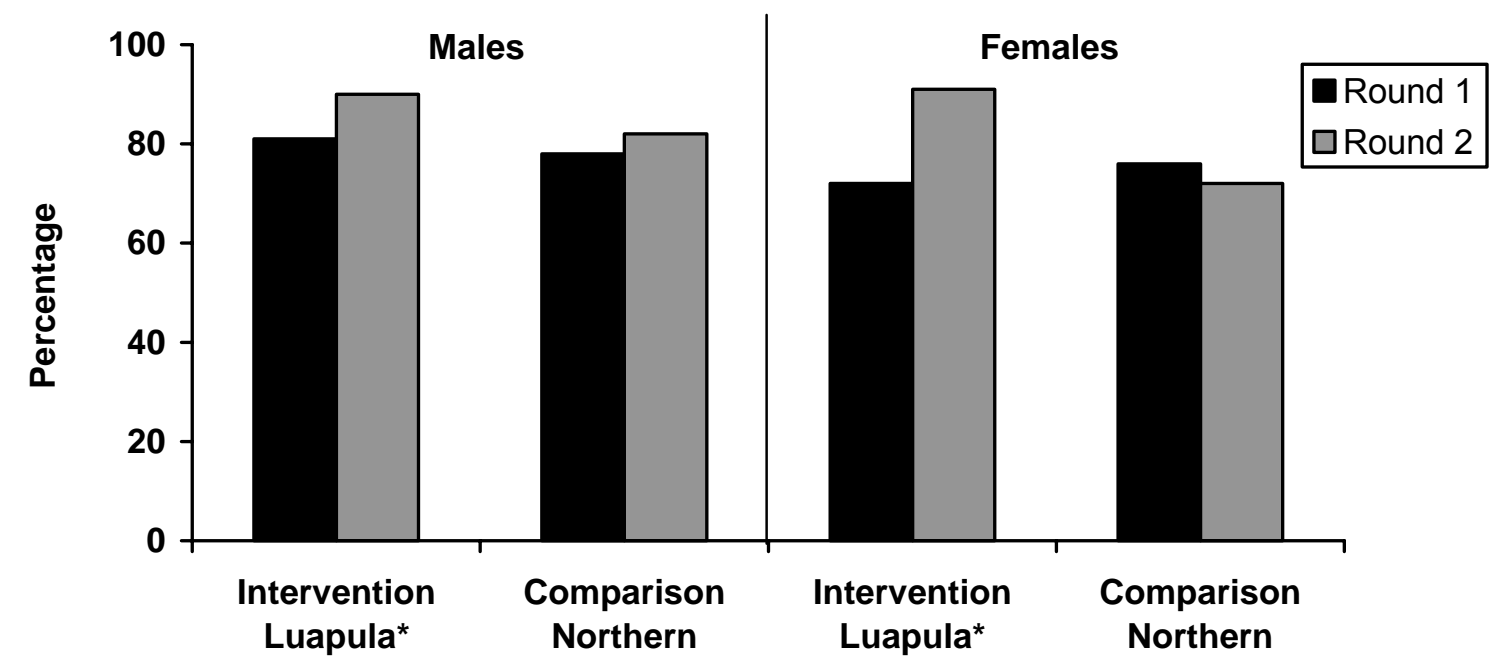

${ }^{*} p \leq 0.05$ 
The purpose of the following section is to understand the effects of the caregiving intervention in Luapula, rather than to document a comparison with Northern Province. Care and support activities were not actively encouraged or supported in Northern Province, although a small number of youths there reported engaging in care activities. Therefore, results presented below focus on the trained youth caregivers in Luapula Province alone, to provide useful information on the nature and requirements of the intervention.

\section{Client needs}

The capacity-building and support needs for caregivers were determined mainly through the formative study. Researchers continually investigated the care and support needs of clients as the care and support services progressed, using feedback from the clients and the caregivers.

Qualitative research with clients receiving the services provided by the youth caregivers indicated that they really appreciated help with their domestic chores, bathing, dressing wounds, referrals, transport to the clinic by bicycle, training family members, and counseling. Youth were generally perceived by clients to be respectful, well informed, highly skilled, and well trained. The youth caregivers' skills in treating sores were particularly valued, because clients experienced less pain and could thus do more for themselves. However, both youth caregivers and clients reported dissatisfaction with the youth's inability to meet material needs, including food, medicine, and general transportation.

The caregivers helped by cleaning the sores, and they have healed. My problem is that I can't afford to buy food and the necessary medicines. (Client, Mantumbusa)

These findings were consistent with the results of the quantitative surveys with the youth caregivers, and were similar for males and females. Youth reported that the services that they were most able to provide help with were cleaning ( 86 to 88 percent), counseling (43 to 45 percent), and bathing/dressing wounds (47 to 52 percent). According to the youth caregivers, the remaining unmet needs of clients identified were felt to be food ( 72 percent), money (58 percent), drugs/medicines (53 percent), and transport (32 percent). Trained youth caregivers felt that they required additional training on counseling ( 58 percent), first aid (53 percent), nutrition ( 31 percent), and VCT ( 29 percent) to improve the services they provided.

Contrary to early concerns that youths would only carry out tasks conforming to sociocultural gender norms, researchers found that male and female caregivers in the intervention areas provided similar kinds of caregiving services (Figure 6). Clients reported that the sex of their youth caregiver was not an issue as long as they could trust the caregiver to provide good services. One exception was bathing, which both youth and clients both agreed should be handled by a same-sex caregiver. For their part, youths said that the most important factor, transcending age and gender concerns, was to make clients feel comfortable about who is providing care to them. It was acknowledged that the more physically demanding tasks (e.g., digging the garden, cutting firewood, repairing the roof) should be reserved for male caregivers, while lighter domestic tasks (e.g., washing plates or 
clothes) are easier for girls to manage. Tasks generally agreed to be suitable for caregivers of both sexes included dressing wounds and general cleaning chores.

Some [clients] worry about whether they are cared for by a boy or girl. But their main concern is whether we do the things that help them, not which sex we are. (Youth caregiver, Mabumba Community Club)

There are certain tasks which must be done by same-sex caregiver such as bathing and sometimes dressing wounds. (Youth caregiver, Muchinka Youth Club)

Clients reported that the youth caregivers visiting them were competent in their duties. Youth caregivers have provided basic training to their clients in how to care for themselves, for example, teaching them to better manage physical ailments (e.g., sores and rashes). Youth caregivers also encouraged and trained family members to perform some of these tasks, such as bathing and dressing wounds. These exercises built the capacity of clients and their family members and have increased the sustainability of the program. The visibility of the caregivers' visits has also motivated others in the community, including other relatives and neighbors, to be more accepting and supportive of clients.

We are teaching the families to care for patients. We monitor by watching if there is the right response to our teaching (Youth caregiver, Muchinka Youth Club)

Figure 6 Care and support services provided by Luapula youth at round 2

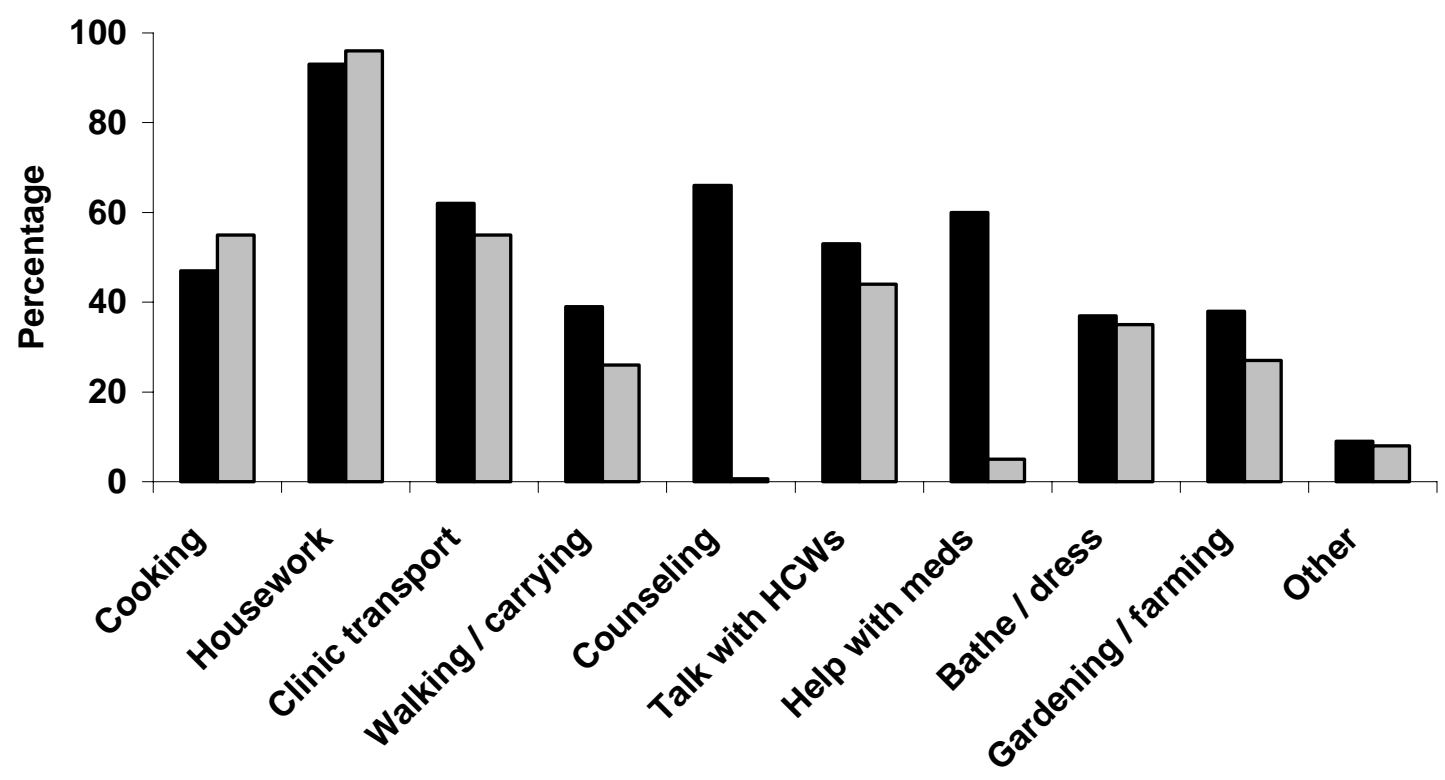

Intervention males $(\mathrm{n}=258) \quad \square$ Intervention females $(\mathrm{n}=195)$ 


\section{Program responses}

Male and female caregivers alike appear to have been well received by the clients; trained youth caregivers reported that over the period of the intervention clients had become friendlier and requested more visits. Almost all (95 percent) youth caregivers reported a change in the attitudes of clients toward them, including becoming more friendly and trusting, and increased disclosure of HIV status (Table 6).

Table 6 Changes observed among clients (of those who have observed change) Round 2 only Intervention males Intervention females Luapula $(n=262) \quad$ Luapula $(n=193)$

\begin{tabular}{lrr}
\hline More disclosure of HIV status & 53 & 53 \\
More friendly & 91 & 90 \\
Greater trust & 19 & 12 \\
Request for more visits & 49 & 59 \\
Introduced other clients & 10 & 8
\end{tabular}

Trained youth caregivers reported that they too experienced a number of benefits from being involved in caregiving activities, including achieving satisfaction from serving their communities, gaining the respect of communities and leaders, increasing their own knowledge and skills, undertaking income-generating activities, and achieving a new status that permitted access to institutions and services. Some individuals also said that the caregiving activities had provided them with the motivation to change their own sexual behavior, although little evidence of this was found among the group as a whole (see section on risky behaviors, page 35). However, despite the benefits of the program, some youths reported experiencing emotional distress when caring for people with needs that were beyond their capabilities, such as dealing with rejection and family disputes, funeral arrangements, or severe hunger.

\section{Meeting OVC needs}

The study originally focused on meeting the needs of clients, but trained youth caregivers soon began reporting that children of clients also required care and support. For the purposes of this study, we use the term OVC to refer to children who have lost one or both parents, or their primary caregiver. Most of the OVC cared for in this study were between 6 and 15 years old.

Children and other dependents of clients were often found without food or other basic needs, providing care to sick household members, absent from school, or left on their own. As a result, the intervention was expanded to address OVC needs. The trained youth caregivers were encouraged to devise initiatives to involve $\mathrm{OVC}$ in recreational activities in an attempt to reduce their sense of isolation, to contact schools to make sure that their needs are recognized, and to make referrals to 


\section{Hgrizons}

NGOs working with OVC in cases where additional support is required. Figure 7 indicates that the services most commonly provided by youth caregivers to OVC during the intervention were counseling, help with household chores, contacts with clinics and schools, and help with bathing and dressing. Small gender differences were observed in the types of services provided to OVC, with the possible exception that male caregivers were more likely to report making contacts with external organizations (NGOs, schools, clinics).

\section{Figure 7 Care and support services provided to OVC by trained youth caregivers at round 2 (of youth who said they provided services to OVC)}

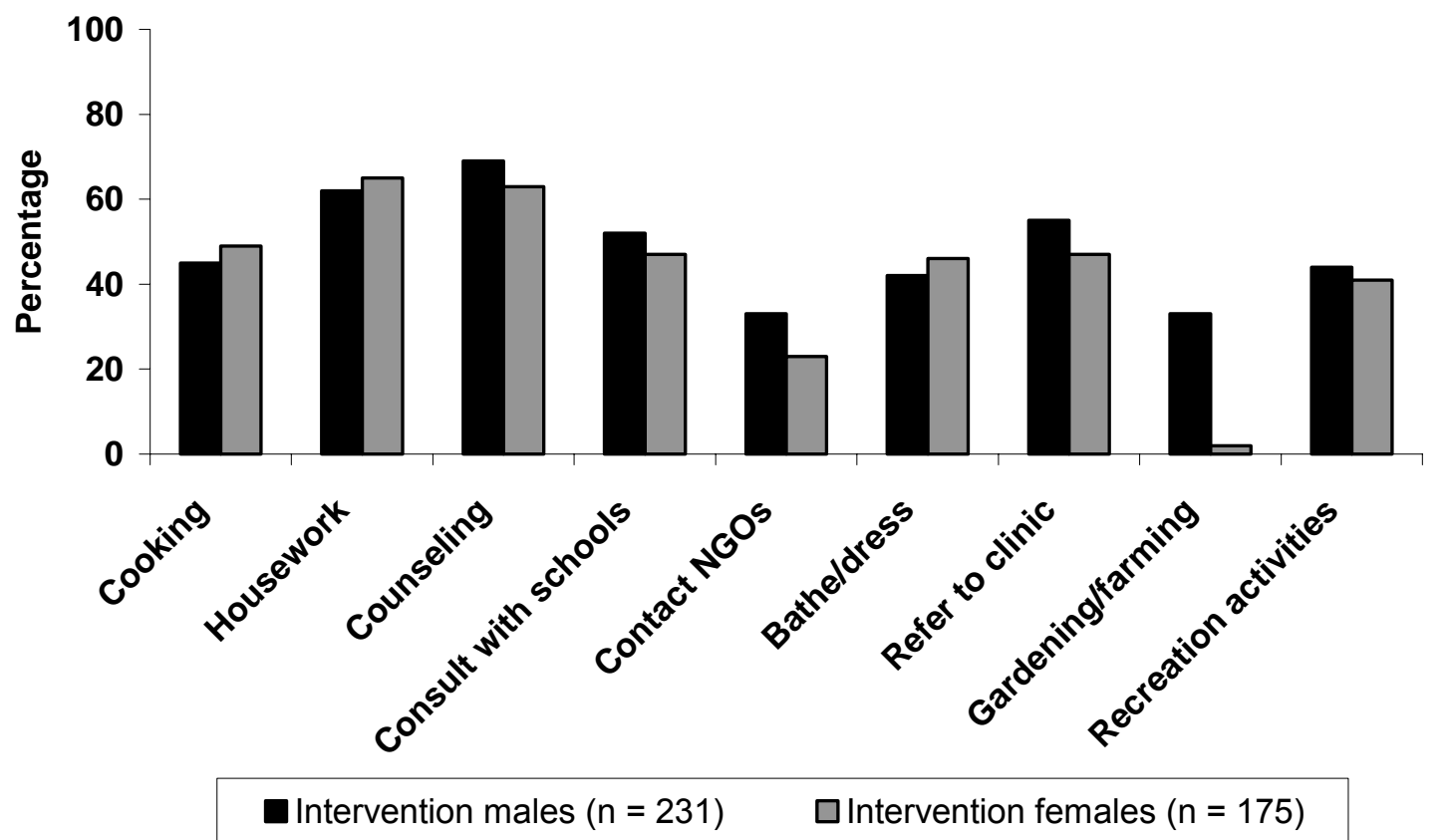

\section{Partnerships}

Partnerships with local community groups and institutions provided crucial elements of support and reinforcement to the activities of the youth caregivers. Local partnerships helped to address challenges experienced by youth caregivers, and provided support in problem-solving and community mediation. They also enhanced the credibility of the youth caregivers in the community by providing increased acceptance and support, which in turn reinforced youth motivation for their new responsibilities. 


\section{Figure 8 Partnerships between youth caregivers and other local bodies}

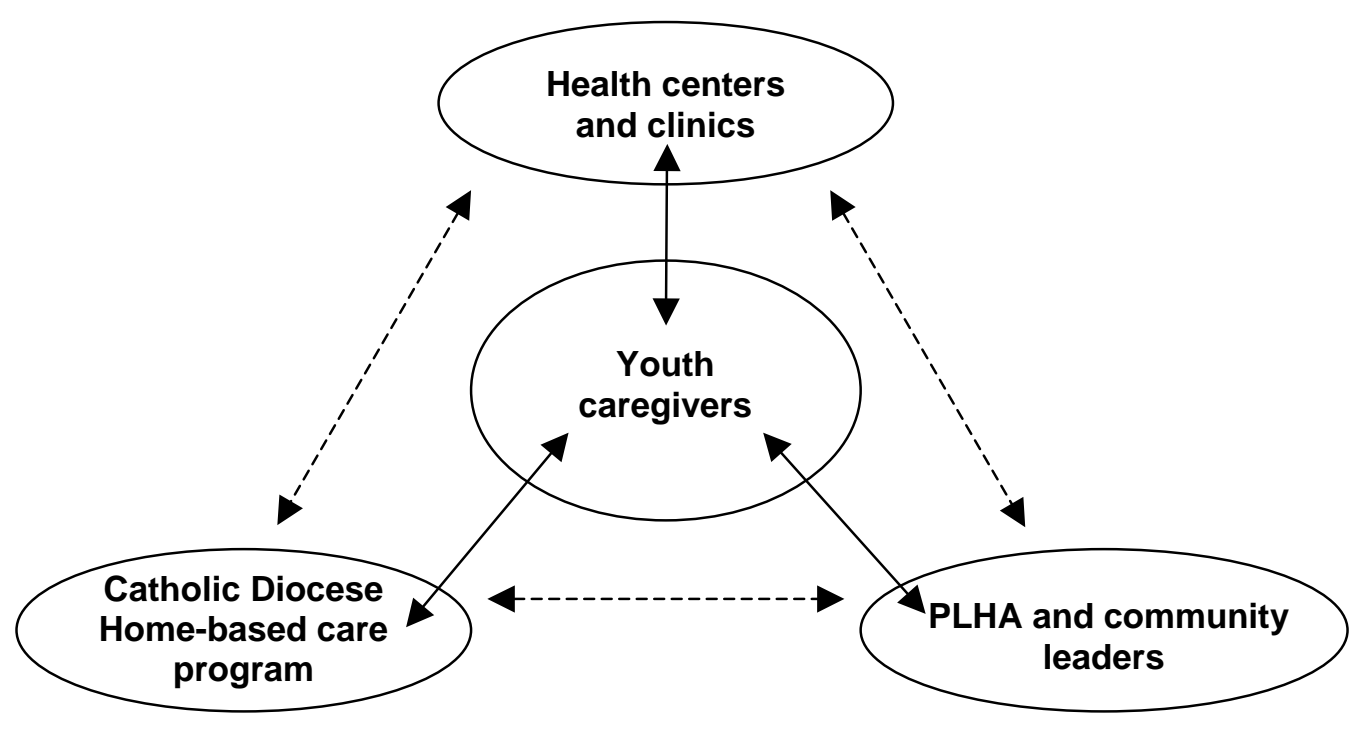

As illustrated by the diagram above, the services of youth caregivers were linked by partnerships with local groups, some of which turned out to be mutually beneficial for both parties.

In particular, the Catholic Diocese for many years worked through the hospital system to provide care for people living with HIV and AIDS, and by 2000 had recognized the need to provide homebased follow-up care. That year, the Catholic Diocese began training adults in Mansa in homebased care and became interested in working with youth as caregivers. This presented a natural opportunity for collaboration with the intervention study: adult caregivers in the Diocese homebased care program teams were assigned to work with youth caregivers-in-training.

Involvement of community leaders was particularly important during the initial stages of the program, to promote acceptance of youth caregivers, generate community support, and enhance access to people living with HIV and AIDS and existing community services.

Headmen go ahead of time to inform the community of our care and support activities. (Youth caregiver, Mutiti Basic School Club)

Our village head gives us protection and if a problem arises, he is there to solve it. (Youth caregiver, Kampampi Basic School Club)

As intervention activities continued and clients began to speak highly of their contact with caregivers, youth caregivers gradually earned the respect of the communities in which they were working. 


\section{Hgrizons}

We are no longer called Anti-AIDS club members but caregivers.... (Youth caregiver, Kabuta Basic School Anti-AIDS Club)

The communities are changing and becoming more involved. They no longer chase caregivers away, they prepare food for us and sometimes donate things which we give to [clients]. (Youth caregiver, Mulilwa Community Club)

Development of local partnerships was necessary to address challenges experienced by youth caregivers and enhance their credibility. Table 7 indicates the range of benefits achieved by community partnerships, as expressed in focus group discussions with youth, at stakeholder meetings, and at dissemination workshops. The broad reach of these partnerships helped to promote general community acceptance of and support for youth as caregivers. 


\section{Table 7 Benefits of partnerships}

\section{Partnership with... Benefits}

Adult home-based care teams (Catholic Diocese Mansa, District AIDS

Taskforce Nchelenge)

Health centers and clinics

Community leaders

Clients living with HIV and AIDS and family members
- Provided supervision, monitoring, and psychosocial support to youth caregivers.

- Existing program framework enhanced potential sustainability of youth care and support program.

- Facilitated the identification of clients in need of services.

- Trained youths gained knowledge of the services that they are promoting (e.g., VCT, TB treatment) and when to refer.

- Acceptance of youth caregivers by clinic staff enhanced the credibility of the youth caregiver program.

- Clinic staff referred clients to youth caregivers to meet appropriate care needs in community settings.

- Collaboration between caregivers and clinics enhanced the consistency of care messages through educational activities.

- Members of clubs linked to health centers were more able to gain access to testing and counseling services for themselves and for referrals.

- Endorsement of program by community leaders enhanced community acceptance of youth caregivers' activities.

- Access to leaders helped youth caregivers address conflicts that arose as a result of their activities.

- Well-respected community leaders were able to identify and refer new clients to youth caregiver services.

- Involvement of community leaders helped address community stigma.

- Responding to the opinions of clients living with HIV and AIDS expressed through support groups provides feedback that will improve the quality of services provided by youth caregivers.

- By working through support groups, clients can better organize income -generating activities, strengthen care activities, articulate their needs and advocate for community support.

- Educated and trained family members can become more accepting and take up some care responsibilities.

- Clients referred other clients to caregivers. 


\section{Hgrizons}

\section{Stigma}

During the period of this study, "red ribbon" stigma reduction campaigns were conducted in both comparison and intervention areas. Additional activities that addressed stigma in only the intervention area included the formation of support groups for people living with HIV and AIDS, specific advocacy activities conducted by trained youth caregivers to encourage support of AIDSaffected families, involvement of village heads, educational activities by people living with HIV and AIDS in clinics and community, and increased visibility of the program in the targeted communities.

Approximately one-fifth of youth in both study areas at baseline said that they felt that people living with HIV and AIDS were treated badly in the community. The most commonly cited examples of bad treatment were isolation and rejection, verbal abuse, rumors, and gossip, many of which were felt to be worse in the villages than the semi-urban areas. Even family members, friends and neighbors, and church and community members were named as potential sources of stigma. Children and family members of people living with HIV and AIDS were also subject to stigma.

My family isolated me, they did not care either now or when I was in Lusaka. It is like a punishment. (Client, Lukakula village)

Generally the appearance of our bodies-rash, being slim-causes people to laugh at us. (Client, Mansa)

At baseline, 17 percent to 26 percent of club members in both areas felt that people living with HIV and AIDS in their community were treated badly, and there were no significant changes to this indicator at follow-up in either area. Most club members agreed that an HIV-positive man was treated no better or worse than an HIV-positive woman. Most club members agreed that AIDS orphans were treated no better or worse than other orphans in the community.

Almost all indicators used to measure stigmatizing attitudes showed high levels of acceptance of people living with HIV and AIDS by youth in both study areas and survey rounds, with no gender differences, and this was neither increased nor eroded at follow-up. Most youths in both areas said they would feel comfortable shaking hands with, using the same plate as, or working with people living with HIV and AIDS.

The only indicator of stigma that differed between comparison and intervention areas was the question of whether youth felt that people living with HIV and AIDS deserved compassion. In the intervention area, where youth had close contact with people living with HIV and AIDS, 90 percent felt that people living with HIV and AIDS deserve compassion, maintained at 91 percent at followup. However, among youth in the comparison area, this indicator dropped from 79 percent to 67 percent $(\mathrm{p}<0.05)$.

If we laugh at the PLHA we may be laughing at ourselves. (Youth caregiver, Muchinka Youth Club) 
Regular visits to client households by willing and enthusiastic youth caregivers appeared to be an important factor in contributing to changing the attitudes of people living with HIV and AIDS and their family members toward the caregivers and to encouraging family members to care for people living with HIV and AIDS.

Survey respondents in the intervention area reported significant declines in community stigma compared to the comparison area. Respondents reporting that families losing members to AIDS were treated worse than others dropped from 21 percent to 9 percent $(\mathrm{p}<0.05)$, while no similar change was recorded in the comparison area (baseline 25 percent, follow-up 21 percent).

During focus group discussions and support group meetings, people living with HIV and AIDS in Luapula indicated that they felt that their overall situation had gotten much better during the course of the intervention, that in the past they had felt isolated from community activities and people used to be afraid of them and would not buy things from them at the market. However, with frequent visits from the youth caregivers, they felt that stigma was declining, their health and physical appearance were improving, and family members were increasingly accepting of them and aware of their needs. During focus groups, clients also reported that the churches were beginning to be supportive and that people in the community were changing their attitudes. They reported that caregivers have helped them to reclaim their dignity and brought back lost love from family. This in turn enables them to cope better with the lower levels of stigma that still persist.

Our community is beginning to accept PLHA since youth caregivers starting visiting; they are not as fearful as before. (Client, Kale Community)

We have noticed that family members are beginning to take more interest in caring for relatives with HIV/AIDS. (Youth caregiver, Mantumbusa Community Club)

Before my niece became a caregiver, I was isolated and abused by my sister, but now she has made her mother accept me. (Client, Kabende village)

\section{Perceptions of risk, vulnerability, and responsibility}

Youths were questioned about their perceptions of vulnerability to and responsibility for HIV. Survey questions covered young people's attitudes about HIV risks generally and questions about each individual's self-perceived risk.

At baseline, most males and females in both areas believed that females are more vulnerable to HIV infection than males. Figure 9 indicates that by the follow-up survey, the prevalence of this belief increased significantly among males and females in the intervention area, but no statistically significant change was observed among the comparison group. However, during the local dissemination workshops, it became clear that young people had a limited understanding of the concept of vulnerability, which they explained mainly by biological factors. The need to take into 
account the social dimensions of vulnerability of females was discussed only after prompting by research staff.

Figure 9 Percentage of youth believing that females are more vulnerable to HIV

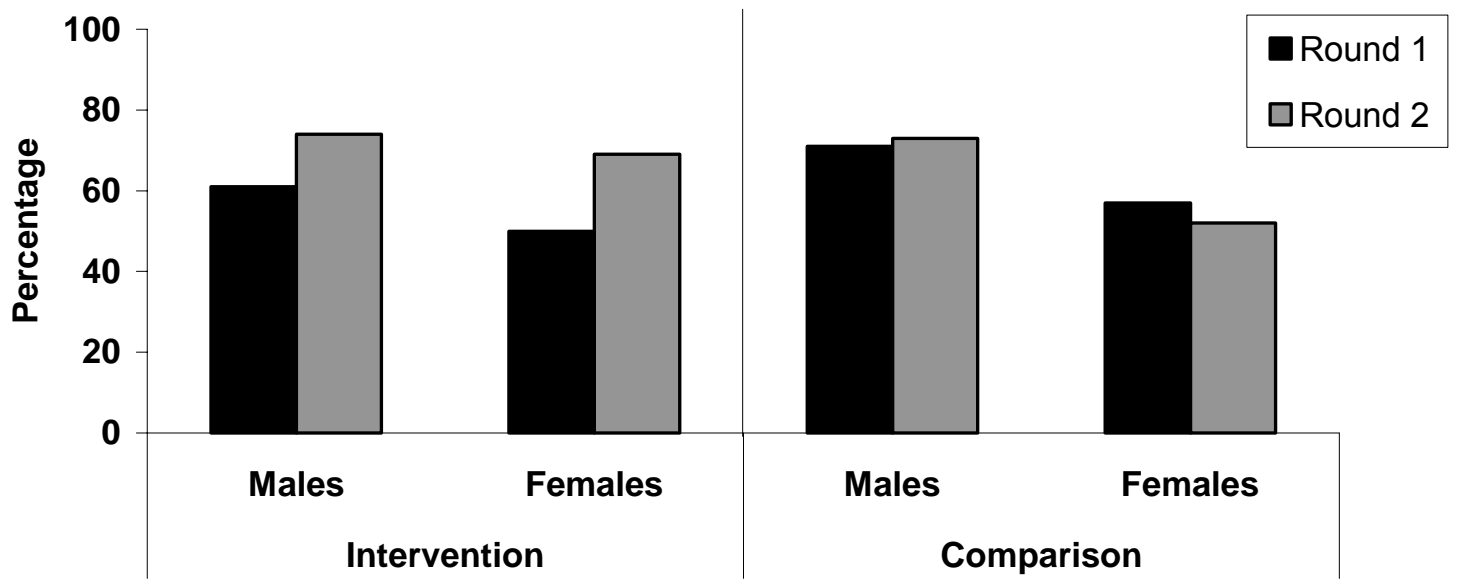

When respondents were asked who was responsible for spreading HIV infection, the typical response in both intervention and comparison provinces was for more males to perceive females as responsible, and for more females to perceive males to be responsible, as shown in Figure 10, with little change between rounds. When these findings were discussed at data interpretation workshops in the communities, some youth attributed the gender differences in perceived responsibility for infection to the lack of trust that characterizes relationships between men and women in general, as well as between young people.

Figure 10 Perceived responsibility for spreading HIV, Luapula Province at follow-up

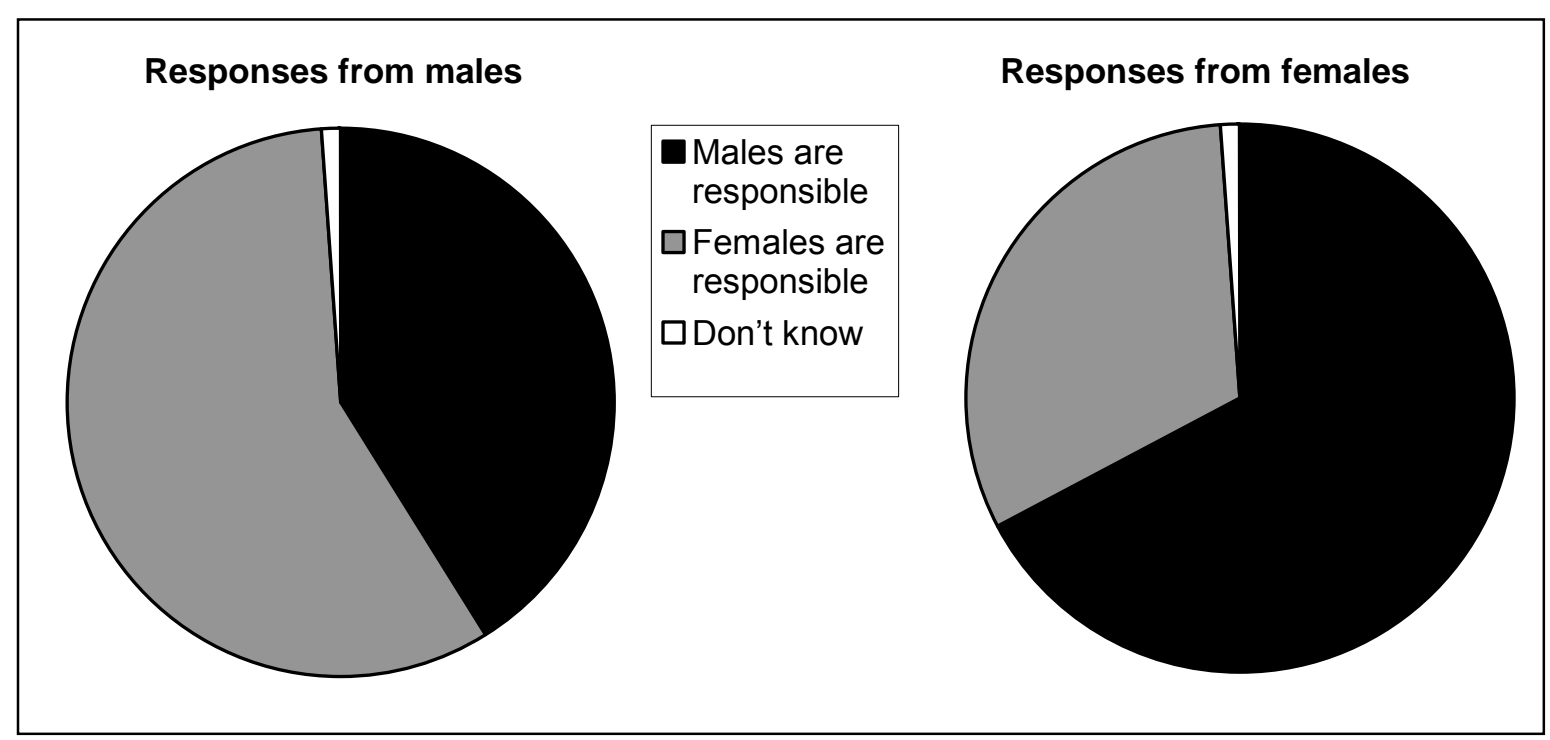


When youth were asked whose responsibility it was to provide a condom, the predominant response from males and females in both study areas at baseline was males (71 to 84 percent of responses). However, by the follow-up survey in the intervention area, the frequency of this response dropped significantly among respondents of both sexes (54 percent to 58 percent of responses), as youth increasingly recognized that supplying condoms could be the responsibility of either the male or female partner. Smaller changes in this indicator were observed in the comparison area (68 to 69 percent of responses). Figure 11 illustrates the example of the changes in the responses to this question among females in the intervention area; similar patterns were observed among males.

\section{Figure 11 Perceived responsibility for providing a condom, among females in intervention area}

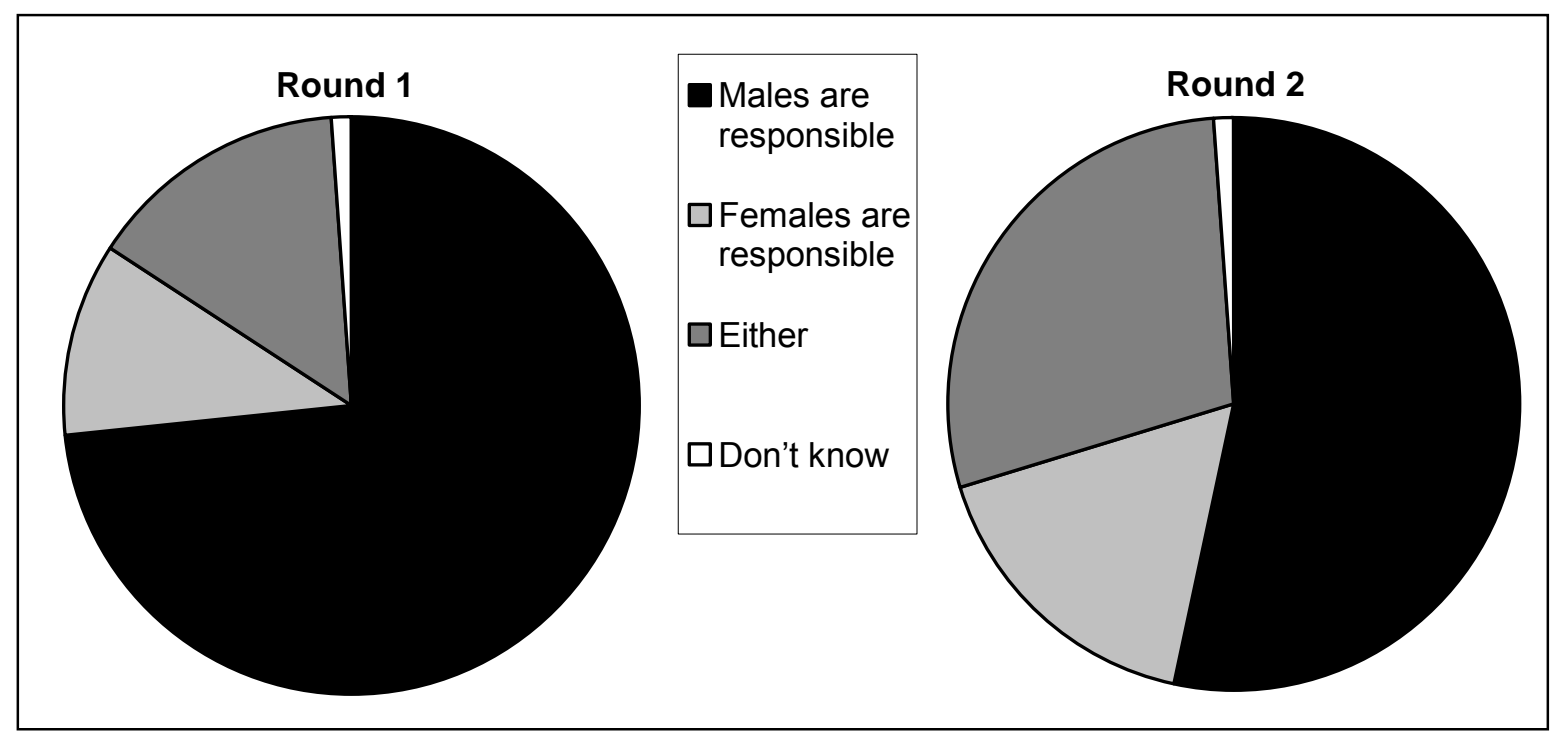

\section{Individual risk self-perception}

Youths were asked to characterize their perceptions of their own personal risk of contracting HIV infection. Figure 12 illustrates the significant changes in the distribution of risk perceptions between the four categories (no risk, small risk, moderate risk, great risk) among males in the intervention area, but similar patterns were observed among females and males in both the intervention and comparison groups. In all groups, youth considering themselves to have no risk of HIV infection declined, and youth considering themselves to have a "small" risk of HIV infection increased. Bivariate analysis indicated that these changes were only significant in the intervention area (Figure 13): males believing that they were not at risk of infection dropped sharply from 76 
percent to 31 percent ( $\mathrm{p}<0.05)$; among females, the drop was from 89 to 41 percent $(\mathrm{p}<0.05)$. Smaller declines were apparent in the comparison area, where youth also received prevention training (males: 61 percent to 51 percent; females: 67 percent to 62 percent, NS). Discussion at the dissemination workshops suggested that the greater changes in risk perception in the intervention area may be attributed to respondents' enhanced awareness of the consequences of HIV through increased contact with people living with HIV and AIDS, some of whom were close to their own age.

Figure 12 Perception of individual HIV risk among males in the intervention area

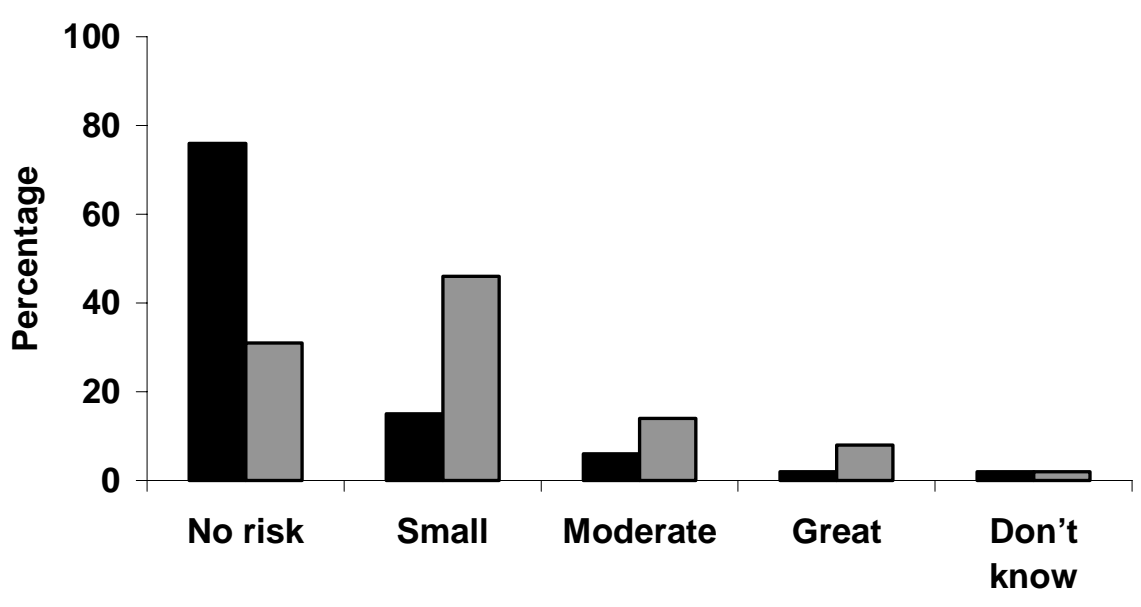

Round 1

$(n=200)$

$\square$ Round 2

$(n=280)$

Figure 13 Youth who believed that they were not at risk of HIV infection
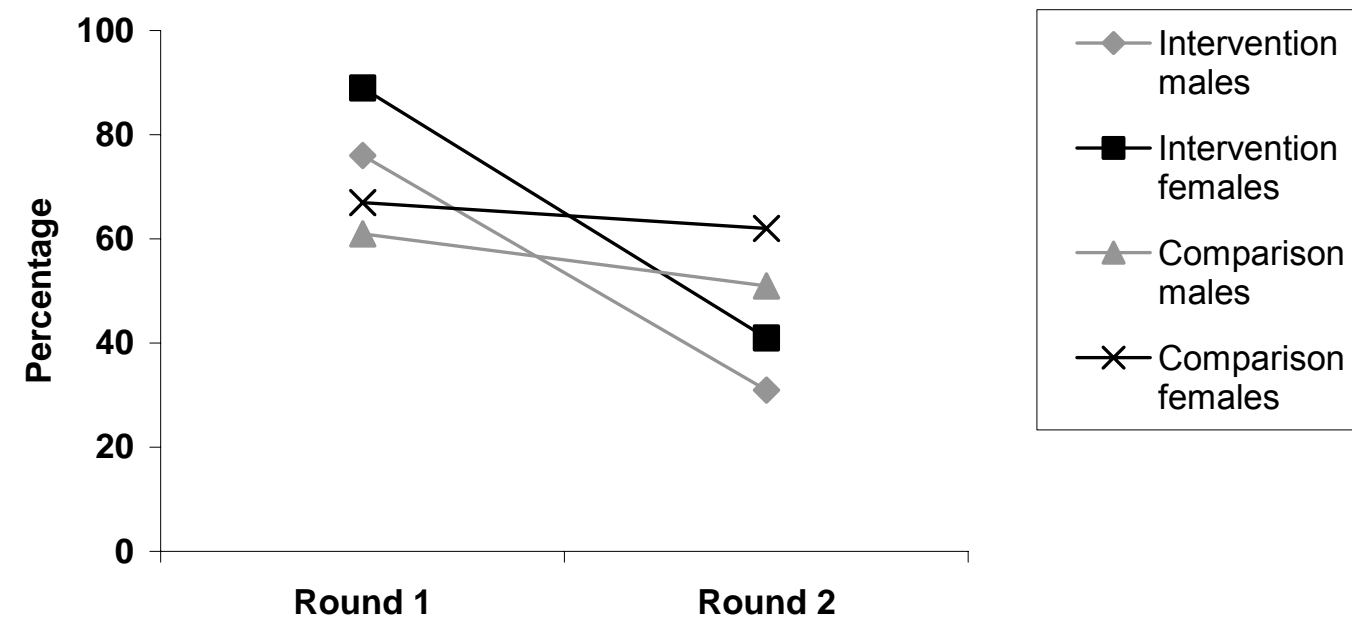


\section{Risky Behaviors}

As with many young people, respondents in this study indicated that peer pressure is an important influence on risk behaviors, including consumption of intoxicants and having a boyfriend or girlfriend. Survey respondents were asked about their exposure during the three months preceding the survey to substances that could influence their risk behaviors. Reported drug use among club members was found to be uncommon, although many respondents noted that they knew of individuals among their peers who used marijuana, glue, or mandrax. Reported alcohol use in the intervention and comparison areas was 16 to 24 percent among males and 3 to 10 percent among females, with no significant changes between rounds.

Youth were questioned about whether they had been forced or pressured by their peers to do anything that they did not want to do. "Forced" in this context refers to the combined effects of peer pressure, which may take the form of coercion or strong influence, as well as the threat of violence. The most common responses for activities that youth of both sexes reported being "forced" into were drinking, having sex, and having a boy/girlfriend. Comments from the dissemination workshops revealed that many youths, especially young women, believe that they do not have the right to say no to sex. Young women in particular perceive that they have little control over their rights. They described the perception that when a girl says no to sex, she is really saying yes, so men do not think they are really forcing her. Additional pressures are faced by orphans who are kept by relatives who may take advantage of them. Participants also mentioned examples of girls being abducted and forced to have sex, which is typically kept quiet by the family.

Both males and females mentioned the exchange of sex for gifts as an added pressure on young people, allowing them to acquire food or money for their family or luxuries (such as body lotion) for themselves (Table 8). For example, between 8 and 16 percent of females reported that they had received gifts from someone who was trying to convince them to have sex. Researchers were particularly surprised by the high frequency of males reportedly receiving gifts to pressure them into having sex (between 6 and 12 percent), which was corroborated by participants in the dissemination workshops who cited examples of boys pressured into sex with older women, often businesswomen (see quotes below). Between 18 and 34 percent of young males indicated that they had given gifts to someone to have sex with them, and this was very uncommon among young women. The use of the threat of physical violence to pressure someone into having sex was reported by up to 11 percent of young women. 
Table 8 Peer pressure and exchange of gifts for sex ${ }^{a}$

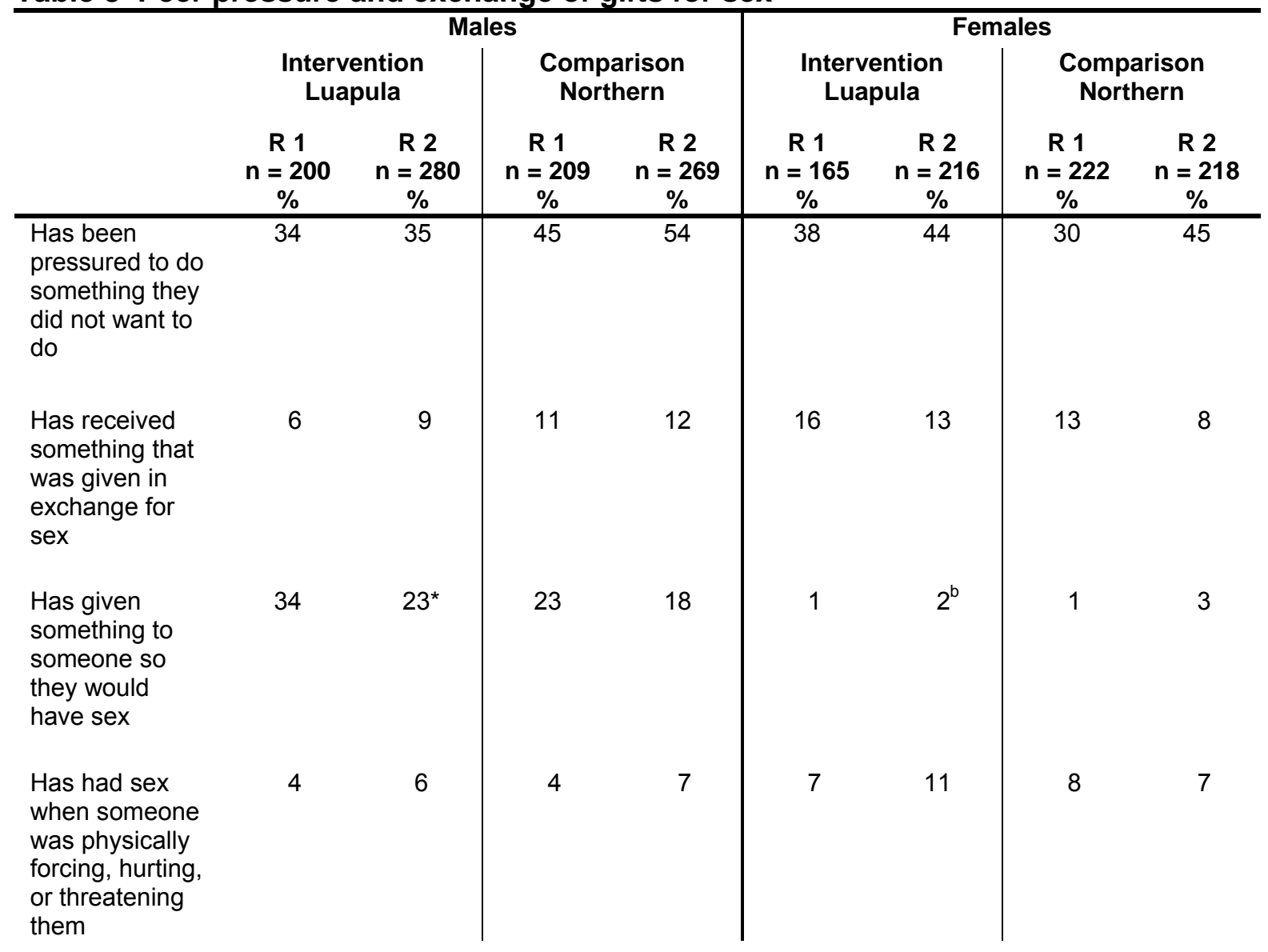

\footnotetext{
${ }^{a}$ Due to skip pattern differences in Rounds 1 and 2, percentages are all based on the total denominator.

${ }^{\mathrm{b}}$ Fisher's exact test used.

${ }^{*} \mathrm{p} \leq 0.05$
}

Qualitative research and comments at the stakeholders' meetings and dissemination workshops revealed that many community members and youths perceive the pressure on young people to have sex in exchange for gifts to be a common and underreported problem, due to the extent of the poverty in the area. Youths explained that sex might commonly be rewarded by transport, money, food, assistance with schoolwork, or photos. The request may not be explicit, but often follows the presentation of a gift, when implied payment is requested.

Many girls lack the things they need, so they agree to have sex in exchange for these things. (Youth caregiver, Mansa High School Anti-AIDS Club) 
I had two girl friends, but loved the one who gave me things. (Youth caregiver, Muchinka Youth Club)

Youths reported that some young people have sex with the adults who are providing them with food or lodging. Discussions with club members highlighted the potential vulnerability of orphans to forced sex and the need to consider forced sex within the extended family. These pressures are not limited to girls: boys may also be pressured to exchange sex for gifts, although to a lesser extent than girls.

There are rich sugar mums who give expensive gifts, and then demand for sex. (Youth caregiver, Mansa High School Anti-AIDS Club)

Ladies want fancy things, but they have no money and ask the shop owner to exchange goods for sex. (Youth caregiver, Muchinka Youth Club)

It is not normal for girls to propose to boys, so they may use gifts as an enticement. (Youth caregiver, Mabumba Community Club)

Youths were also asked about the age difference between themselves and their sex partner, in order to identify cross-generational relationships that may place young women at greater risk of HIV infection, due to their exploitative or transactional nature and inherent power imbalances. In both surveys, only a small number of sexually experienced youths reported having had sex with an adult at least five or ten years older. However, participants at the dissemination meeting revealed that estimating the age of an older sex partner age was particularly difficult for young people, and asking directly would be unusual, especially in the context of casual sex. They believed that many young people who have had sex with older adults would not be able to tell their age.

\section{Reported sexual activity}

Interviews conducted face-to-face regarding sexual behavior may be subject to compromises in validity, since they are vulnerable to typical peer pressure patterns among youth: young men may be prone to boasting and exaggeration, while young women may be reluctant to admit sexual activity at all for fear of being labeled promiscuous. The trends that lead young people to either overreport or underreport sexual activity were openly described by respondents during the data dissemination workshops, and were felt to be particularly influential in the more rural areas.

A girl could be considered to be a prostitute if she says she has had sex, so she would keep it to herself. (Youth caregiver, Mabumba Community Club)

It is not so [the low number of females who report having had sex], it is just that girls are shy to say that they have had sex. (Youth caregiver, Muchinka Youth Club)

In order to be sensitive to local terms and traditions, the interviewers conducting all of the surveys were local people who had been specially trained for this purpose. However, this had an unforeseen 


\section{Hgrizons}

effect: interviewees feared that they might run into or be recognized at a later date by the interviewers, who might remain in their local area, thus introducing an additional inhibition to their responses on sexual behavior.

There were slight variations in mean age limit comparability between the intervention and comparison groups; for this reason, the sexual behavior data analyzed in the sections that follow are based on age-stratified categories.

Figure 14 below illustrates the patterns of reported sexual activity among young men and women in both study provinces. Among all young men, between 15 and 23 percent of survey respondents reported that they had never had sex, and a further 42 to 57 percent of young men had previously had sex but not within the last three months. Combining these groups, between 59 and 79 percent of young men reported no sexual activity during the last three months.

Reported levels of sexual activity among young women were, as expected, even lower. Between 49 to 64 percent of young women said that they had never had sex, and a further 26 to 35 percent said that they had previously had sex but not within the past three months. Combining these groups, between 81 to 91 percent of young women reported no sexual activity during the last three months.

Although some of these distribution patterns changed significantly between rounds, the magnitude of these changes was small, with low programmatic applicability. In addition-as noted in the methodological caveat earlier-it is not possible to distinguish genuine change in behavior from change in comfort level reporting true sexual activity to the interviewer, and the possibility of confounding by religion or other factors cannot be ruled out. Overall, these results indicate low levels of sexual experience and recent sexual activity among male and female club members. 
Figure 14 Reported sexual activity

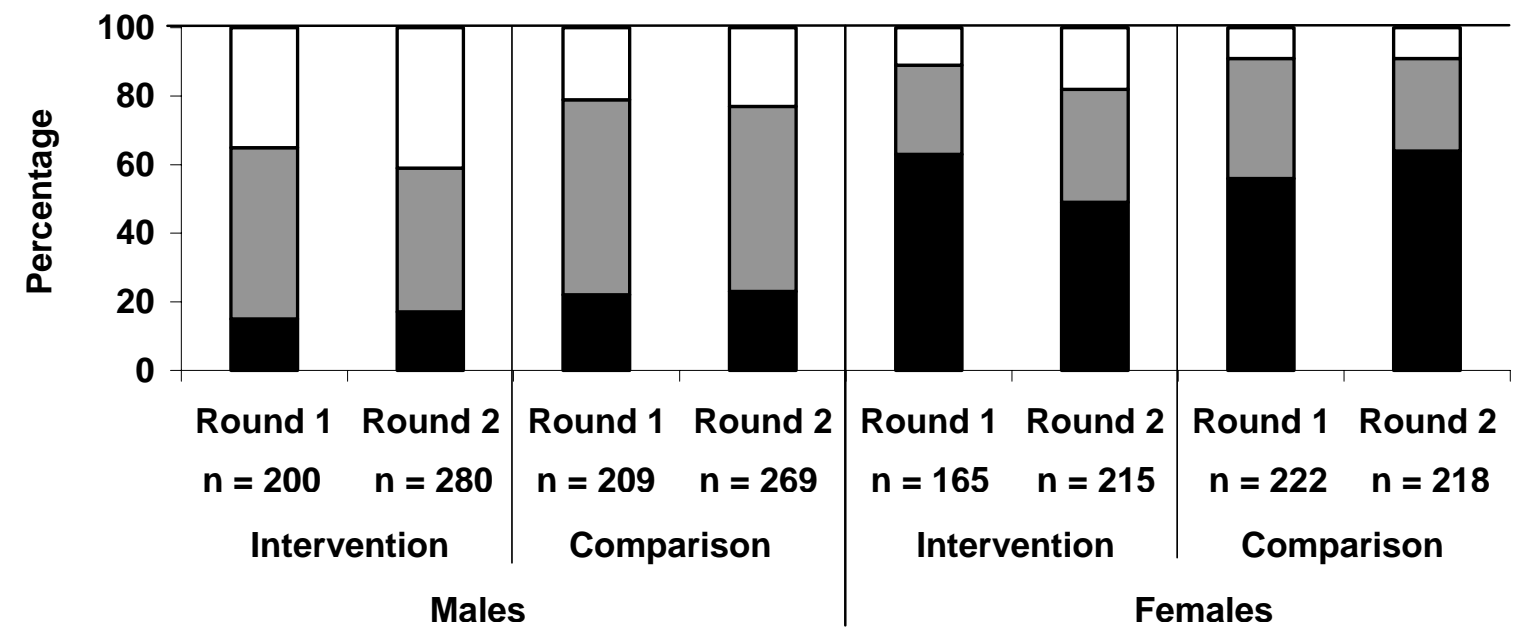

Never had sex $\quad \square$ Had sex but not in last 3 months $\quad \square$ Had sex in last 3 months

Table 9 shows the results of logistic regression odds ratios analyses on the sexual behavior data, controlling for age. It indicates that between rounds, females in the intervention area became 1.59 times more likely to report ever having had sex than at baseline. When controlling for age among males in the intervention area however, logistic regression odds ratios indicated that they were 0.57 times less likely to say that they had ever had sex at follow-up than at baseline. Logistic regression results in the comparison province indicated that the likelihood of ever having had sex for both males and females was unchanged between rounds. This analysis also confirms that there were no significant changes between rounds among youth reporting having had sex within the last three months. Contrary to expectations, membership of a club with a care and support training program did not affect reported sexual activity.

Table 9 Logistic regression odds ratios (OR) indicating probability of change in sexual activity between rounds, controlling for age

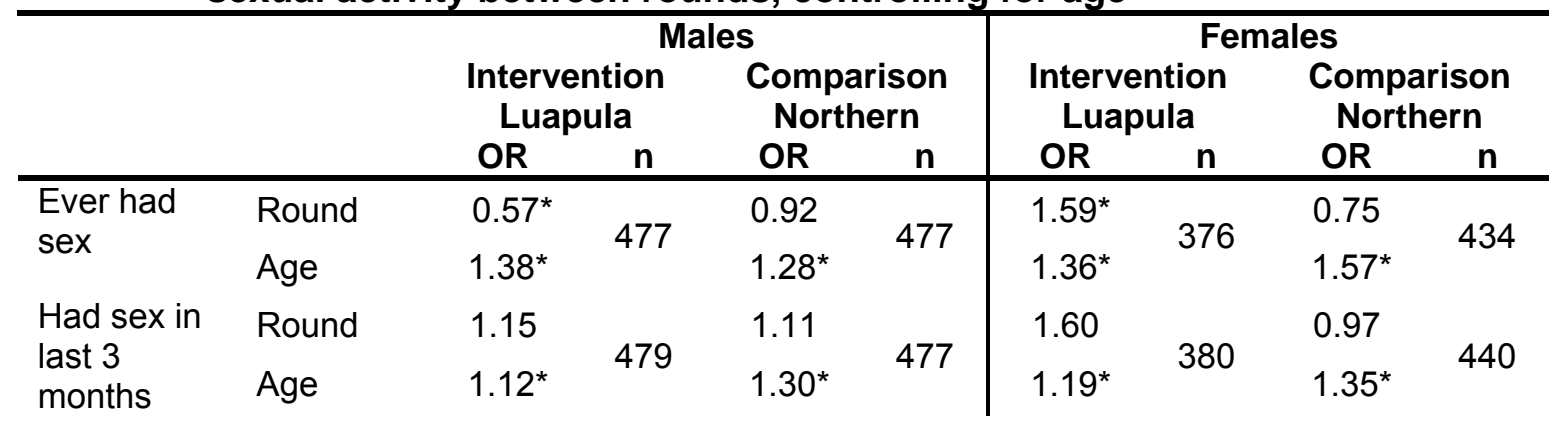

${ }^{*} p \leq 0.05$ 


\section{Number of partners}

As indicated in Figure 14, between 21 and 41 percent of the young men and 9 to 19 percent of young women said that they had had sex within the last three months. Figure 15 shows the number of reported sexual partners of youth reporting sexual activity during the last three months. By far the majority of these respondents reported only one sexual partner during the three-month period, and there were no significant differences in mean values between rounds. Among the young men, it is of concern that a few reported having three or more sexual partners during the three-month period.

Figure 15 Reported number of sexual partners during last 3 months, of youth who had sex during last 3 months

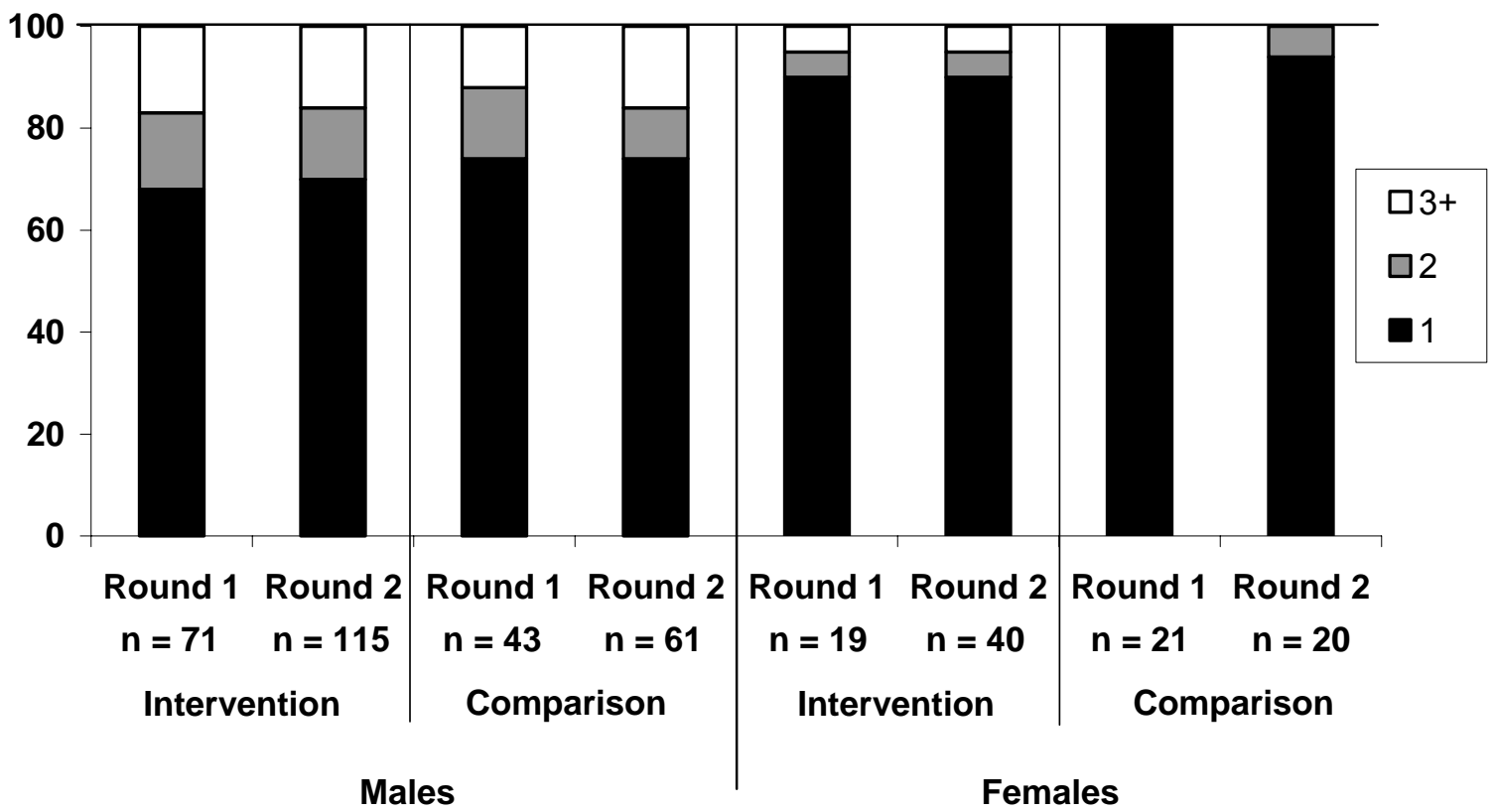

\section{Condom use}

Youths who reported that they had had sex were asked about their use of condoms. Figure 16 below indicates significant increases in ever-use of condoms among those who reported ever having had sex among males and females in the intervention area: from 61 to 81 percent of young men, and from 66 to 81 percent of young women. Meanwhile, in the comparison area no significant changes were detected among males or females. During local dissemination workshops, club members indicated that continuing supply problems affect youth's ability to obtain condoms in these areas. 


\section{Figure 16 Ever-use of condoms among youth who reported ever having had $\operatorname{sex}$}

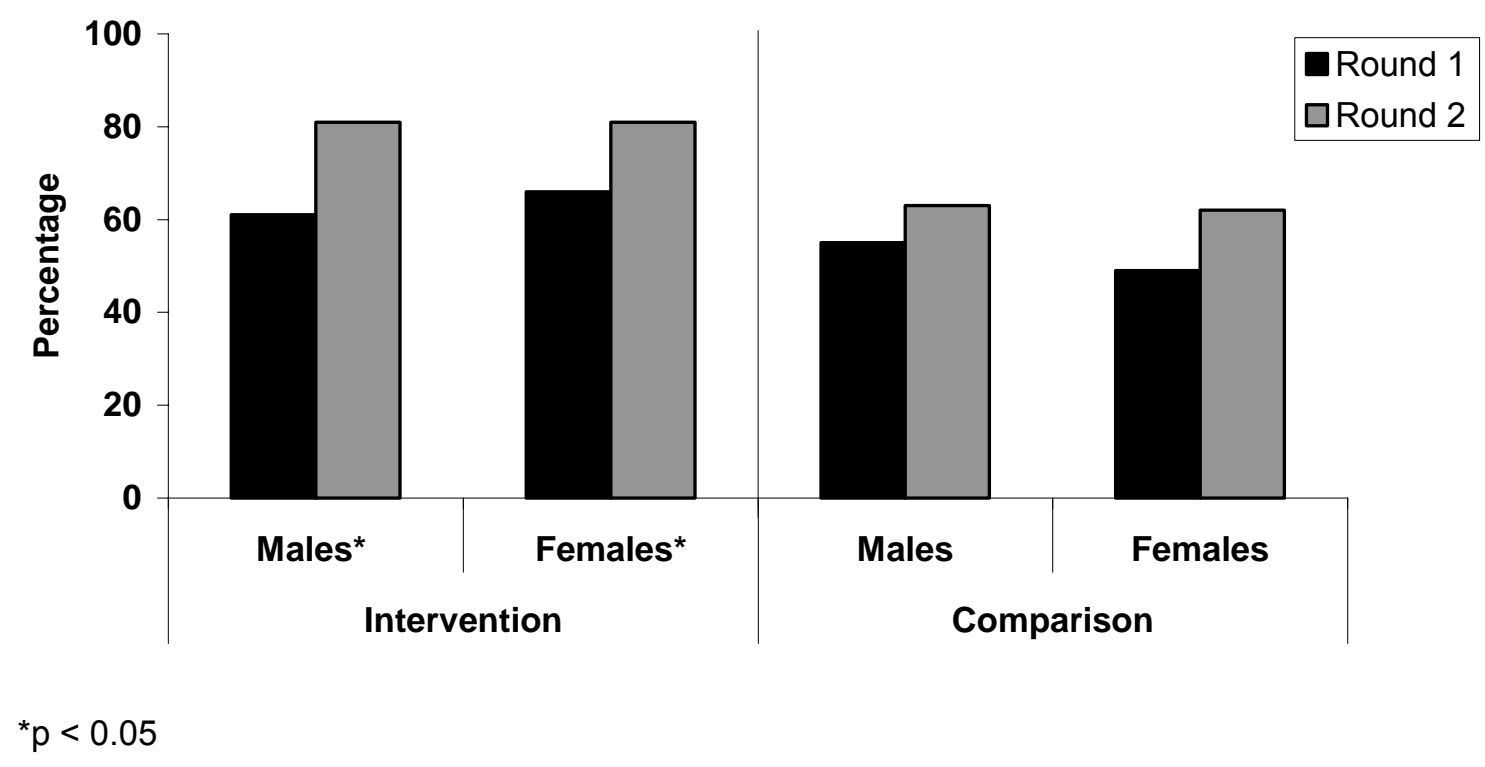

We now know how to use condoms. (Youth caregiver, Mabumba Community)

We have the knowledge of the value of condoms. (Youth caregiver, Mansa High School club)

Youths who reported that they had used a condom at least once were asked if they had used a condom at their last sexual encounter. Between 80 and 90 percent of the young men and women in both study provinces who said that they had ever used a condom reported that they had used one at the last time they had sex. No significant changes over time were detected among youth of either sex at either study site.

Logistic regression analysis (shown in Table 10) was consistent with the results above, confirming that even when controlling for age differentials, the likelihood of having ever used a condom was greater in the second round only for the intervention group. Furthermore, it also indicated that "condom use at last sex" became less likely as the respondents increased with age. This may be an indication that while sexually experienced youth in Luapula became more experienced with having used or tried condoms; this did not necessarily result in more frequent condom use. This may be the result of the youth developing more stable or intimate relationships as they mature, thereby possibly dropping condom use at later ages.

The study team tried to ensure that youth knew where to access condoms locally, and at each site visit tried to bring condoms directly to club members, for their own use and for outreach activities. The main local sources of free condoms was the local health clinic/s, but many young people felt uncomfortable going to a clinic, where the condom supply could not even be relied upon due to 


\section{Hgrizons}

frequent stock-outs and unwelcoming staff who were reluctant to provide condoms to young people. Condoms were also available through the supermarket, local markets, and social marketing outlets (Society for Family Health).

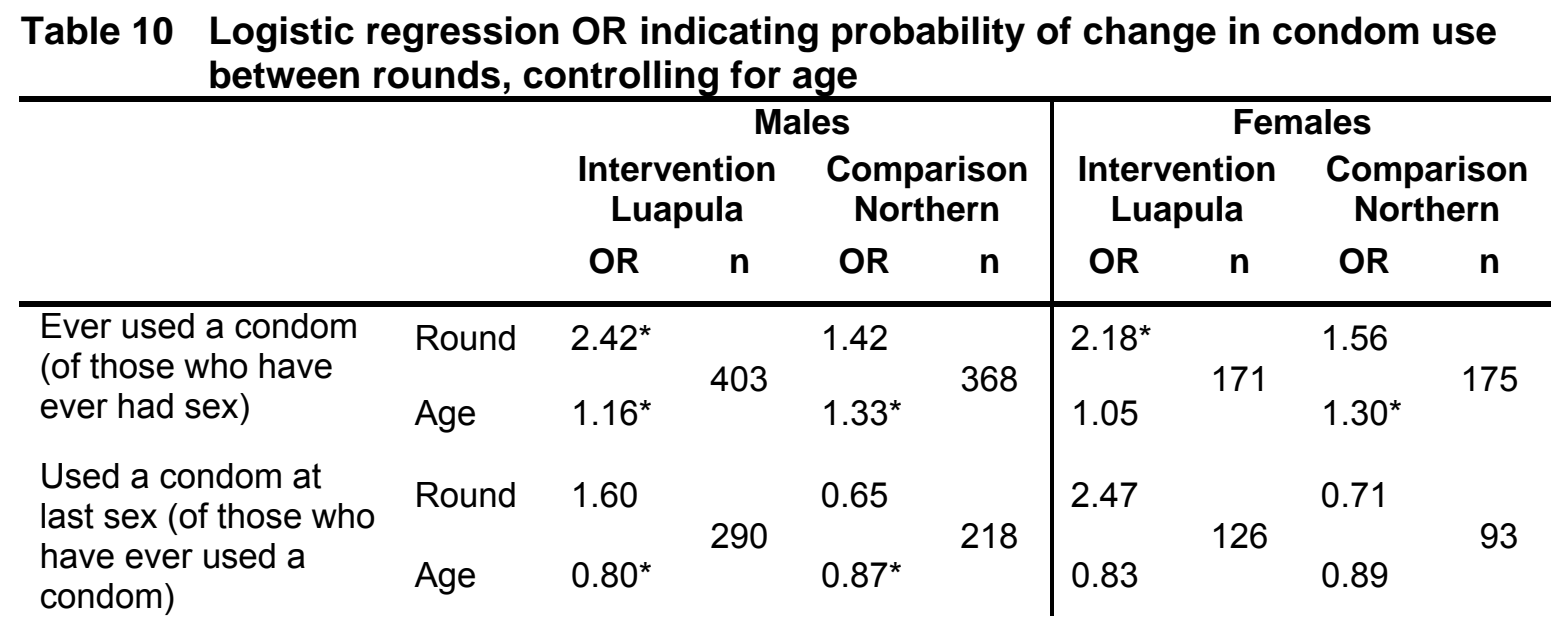

${ }^{*} p \leq 0.05$

\section{Reported behavior change}

During the baseline survey, respondents were asked if they felt that they had changed their behavior since hearing about HIV and AIDS. At the follow-up survey, the wording in the question was made more specific: youth were asked if they had changed their behavior since joining an antiAIDS club (thus, precise significance values have not been calculated). At the dissemination workshops, the participants explained that being a member of an anti-AIDS club was a great motivation for behavior change and that the behavior of club members was qualitatively very different from that of their non-club member peers.

Overall, levels of reported behavior change were varied. Some of the more common ways in which youth reported that they had changed their behavior since hearing about HIV and AIDS were that they had stopped having sex, started using condoms, or reduced the number of sexual partners. These trends were reported in both intervention and comparison areas even before the start of the training.

Table 11 indicates striking increases among youth who reported beginning condom use and those reporting that they had confined sexual activity to one partner since learning about HIV and AIDS. These reported changes in behavior may not be consistent with the sexual activity data reported above due to the lack of a specific time frame used in this question. Although these data may not always reflect the same trends as the sexual behavior indicators above, they may represent respondents' intentions to change and improved prevention awareness. If this is the case, messages 
regarding abstinence and monogamy appeared to resonate strongly with the respondents, and reportedly stopping or delaying sex was higher in Northern Province.

During the period of the intervention, there was an increase among males and females in the intervention area who reported asking their partner to be faithful, indicating enhanced partner communication (Figure 17), while youth in the comparison area remained virtually unchanged in this regard.

After being taught about the dangers of AIDS, we decided to stay away from those behaviors. (Youth caregiver, Mansa High School Club)

We are now educated, and we are taking precautions to avoid the virus. (Youth caregiver, Mansa High School Club)

There is a change in our sexual behavior since we have seen the dangers of HIV/AIDS, and some of us have gone for VCT. (Youth caregiver, Mansa High School Club) 
Table 11 Reported behavior change

\begin{tabular}{|c|c|c|c|c|c|c|c|c|}
\hline & \multicolumn{4}{|c|}{ Males } & \multicolumn{4}{|c|}{ Females } \\
\hline & \multicolumn{2}{|c|}{$\begin{array}{l}\text { Intervention } \\
\text { Luapula }\end{array}$} & \multicolumn{2}{|c|}{$\begin{array}{c}\text { Comparison } \\
\text { Northern }\end{array}$} & \multicolumn{2}{|c|}{$\begin{array}{l}\text { Intervention } \\
\text { Luapula }\end{array}$} & \multicolumn{2}{|c|}{$\begin{array}{c}\text { Comparison } \\
\text { Northern }\end{array}$} \\
\hline & $\begin{array}{c}R 1^{*} \\
\mathbf{n}=200 \\
\%\end{array}$ & $\begin{array}{c}\mathbf{R} 2^{\star \star} \\
\mathbf{n}=280 \\
\%\end{array}$ & $\begin{array}{c}R 1^{*} \\
\mathbf{n}=209 \\
\%\end{array}$ & $\begin{array}{c}\mathbf{R} 2^{\star \star} \\
\mathbf{n}=269 \\
\%\end{array}$ & $\begin{array}{c}R 1^{\star} \\
\mathbf{n}=165 \\
\%\end{array}$ & $\begin{array}{c}\mathbf{R} 2^{\star \star} \\
\mathbf{n}=2^{216} \\
\%\end{array}$ & $\begin{array}{c}R 1^{\star} \\
n=222 \\
\%\end{array}$ & $\begin{array}{c}R 2^{\star \star} \\
n=218 \\
\%\end{array}$ \\
\hline $\begin{array}{l}\text { No behavior } \\
\text { change }\end{array}$ & 1.5 & 1.4 & 0.0 & 1.1 & 1.9 & 4.7 & 2.8 & 6.0 \\
\hline $\begin{array}{l}\text { Didn't start } \\
\text { sex }\end{array}$ & 13.0 & 14.0 & 28.4 & 13.9 & 42.2 & 32.9 & 41.3 & 30.3 \\
\hline $\begin{array}{l}\text { Stopped all } \\
\text { sex }\end{array}$ & 26.5 & 19.8 & 47.5 & 54.9 & 23.6 & 22.7 & 45.4 & 59.2 \\
\hline $\begin{array}{l}\text { Started using } \\
\text { condoms }\end{array}$ & 28.6 & 58.6 & 27.5 & 44.7 & 6.8 & 38.4 & 9.6 & 26.6 \\
\hline $\begin{array}{l}\text { Restricted to } \\
\text { one partner }\end{array}$ & 36.0 & 38.5 & 26.0 & 34.6 & 19.4 & 30.6 & 17.9 & 28.0 \\
\hline $\begin{array}{l}\text { Reduced } \\
\text { number of } \\
\text { partners }\end{array}$ & 12.0 & 16.2 & 10.8 & 16.2 & 4.3 & 9.3 & 7.4 & 7.8 \\
\hline $\begin{array}{l}\text { Asked } \\
\text { partner to be } \\
\text { faithful }\end{array}$ & 3.0 & 14.0 & 7.8 & 8.3 & 0.6 & 4.6 & 6.9 & 5.0 \\
\hline Other & 12.1 & 12.6 & 16.6 & 15.1 & 12.4 & 9.7 & 29.4 & 12.8 \\
\hline
\end{tabular}

*Round 1: behavior change since hearing about HIVIAIDS

${ }^{* *}$ Round 2: behavior change since joining anti-AIDS club

Figure 17 Youth who reported that they asked partner to be faithful

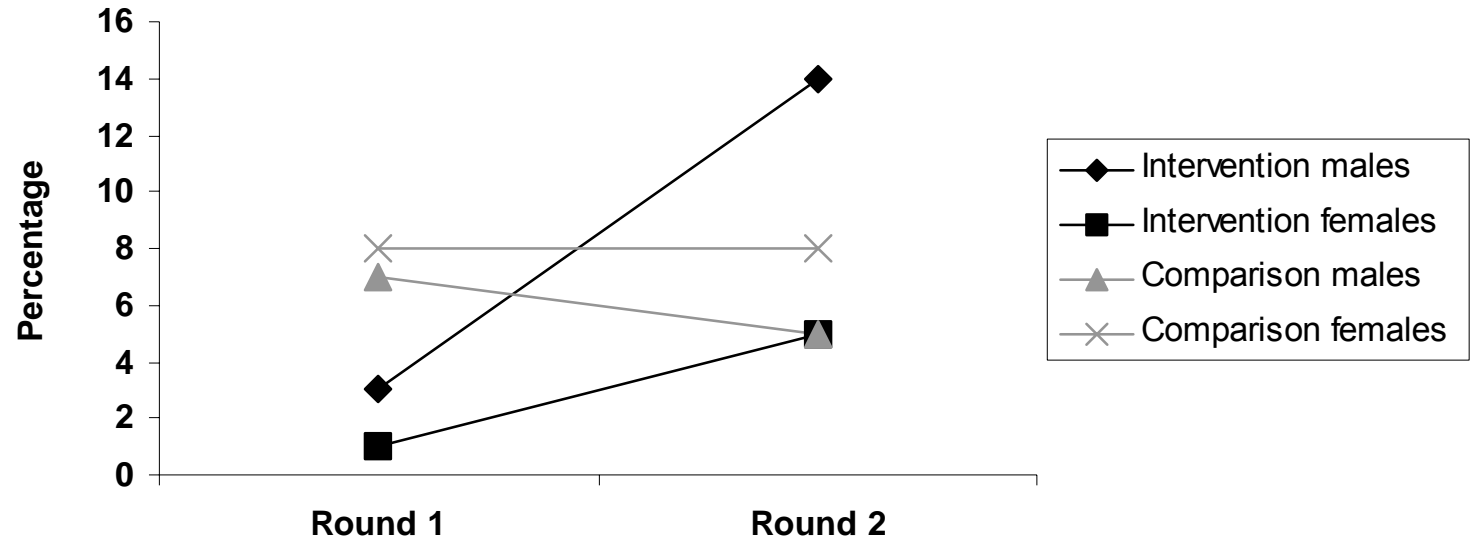




\section{Conclusions}

This study demonstrated that trained youth caregivers were able to meet a range of client and OVC needs, to the satisfaction of their clients, and that their efforts may be laying the foundation for decreased isolation and stigmatization of AIDS-affected families. Despite the limitations of the study design, which required researchers to use a comparison group rather than a strict control, the study findings suggest how youth can be empowered to confront the realities of HIV in their own lives and communities, while simultaneously serving as a valuable resource to people in their communities who are living with HIV and AIDS.

\section{Trained youth were well suited to serve as caregivers.}

Club members were highly suited to the role of "caregiver" because they were keen to volunteer, enthusiastic about learning and implementing new skills, and knew their communities well. Flexible, literate, and knowledgeable about HIV and AIDS, the youths were easy to train and accommodating in terms of their availability and the types of work they did. Youth caregivers showed impressive openness to networking and collaborating with other community care resources.

\section{OVC emerged as a key concern, to which trainers and youth responded.}

Caregiver training and support were modified in light of the discovery that one of the ways in which youth could best provide reassurance to their clients was to also offer services to their dependents. Youth caregivers ran recreational activities for OVC to reduce their sense of isolation and forged connections with local schools, clinics, and NGOs providing services to OVC.

\section{Regular caregiving visits by youth were associated with a reduction in community stigma.}

Regular visits to households of people living with HIV and AIDS by willing and enthusiastic trained youth caregivers appeared to be an important factor in contributing to changing attitudes among family and community members. 


\section{Youth caregivers can address the concerns of family members and build their capacity to provide care to people living with HIV and AI DS.}

Encouraging family members to provide care is important to the emotional well-being of people living with HIV and AIDS. When families provide care themselves, services are sustainable and stigma is likely reduced.

\section{Innovative interventions can be implemented even in remote locations.}

This study demonstrated that youth and community groups in relatively isolated rural and semiurban areas can provide positive and enthusiastic responses to interventions and show high levels of participation. There is great demand for more activities to be conducted in locations far from the bigger and more urbanized areas, where many interventions are already in place.

\section{Community involvement and partnership are essential.}

Involving community leaders is vital to the acceptance and success of the activities of youth caregivers. Partnerships with local institutions extend the scope of services beyond what youth can provide alone, legitimize youth caregiver services, and increase all partners' understanding of each other and the ways in which they can meet the needs of clients and OVC.

\section{Training that addresses gender concerns can make a difference.}

Despite initial fears, after appropriate training, young women and men successfully overcame gender concerns to provide a range of services that were well received by their clients.

\section{Effects of the intervention on sexual behavior were limited.}

The extended contact between clients and trained youth caregivers during the short period of this study was associated with low-magnitude changes in condom use.

This study has clearly shown that involving youth in care and support activities provided an inexpensive method for providing much-needed care services for people living with HIV and AIDS. With appropriate training and back-up, young people can serve as a resource to their own communities, provide a service that is genuinely appreciated by their clients, and even have an wider-level impact on mitigating stigma in the community. 


\section{Recommendations and Next Steps}

Horizons and partners are currently implementing an 18-month program to mobilize local resources and promote local management. The goal is to transfer ownership of the program to the community to sustain youth involvement in care and support activities. A particular focus of the continuing study is to further strengthen local partnerships and expand network linkages to promote community ownership and sustainability. Implementation partners, including Catholic Relief Services and the Mansa Catholic Diocese, continue to adapt the project for scaling up in other communities in Luapula and Northern provinces.

We offer below some of the key practical recommendations based on the lessons learned during the course of this study for other organizations looking to replicate or scale up this model of training youth in care and support, and also for related programs training youths in HIV prevention.

\section{Care and Support I nterventions}

- Involve community leaders to promote acceptance of youth caregivers, generate community support, reduce stigma, and enhance access to existing community services that provide support to people living with HIV and AIDS. Involving village heads and traditional community leaders is necessary to earn community respect.

- Clearly articulate and communicate the range of needs that youth caregivers are equipped to meet. The limitations of caregiver capabilities must be clearly communicated to clients and caregivers to avoid raising false hopes and expectations of receiving food or medicines or placing demands on caregivers that they are not equipped to meet.

- Institute ongoing monitoring and training to strengthen capacity and improve services provided by youth caregivers. Youth caregivers may require psychosocial support to address stress and burnout. Support for ongoing monitoring and training can be enhanced by local partnership.

- Provide bicycles to help youth visit isolated clients living in remote areas and transport them to clinics. Use and ownership of and maintenance responsibilities for the bicycles must be clearly defined and agreed upon before they are introduced.

- Replenish consumable supplies in the care kit on a regular basis. Meeting this need reaffirms the value of caregiver activities and builds their confidence.

- Address cultural concerns about gender-appropriate behaviors during the initial stages of training by promoting discussion among youth and identifying barriers that can be overcome. 


\section{Hgrizons}

- Establish formal and informal collaborations and partnerships to improve access to treatment for clients seeking medical attention and for others seeking VCT, and improve caregiver knowledge of when and how to make referrals. Partnerships with local institutions, including $\mathrm{HBC}$ and OVC programs, can help to address the range of needs of clients and their families.

- Involve people living with HIV and AIDS in the design of care and support programs, offering individuals the opportunity to articulate their own priorities and needs to thus increase the acceptance and coverage of community care and support activities. PLHA involvement is feasible in isolated rural areas, even where community stigma is high.

- Promote local ownership and management to take the program beyond the research phase and to promote sustainability and continuity. Instrumental to this process is identifying opportunities and strategies for partnership and integration of youth care and support activities into existing or planned programs.

\section{Prevention I nterventions}

- Help young people to appropriately determine their personal risk of HIV and AIDS. Programs working with young people often focus on ensuring that they are aware of HIV and AIDS and know the facts about transmission, without necessarily ascertaining that they understand how these facts relate to their own lives. Even young people who are well informed about the general facts of HIV prevention can believe that they are personally immune from infection when it comes to assessing individual risk. Effective strategies are required to enable young people to appropriately determine their personal risks of HIV infection and to sustain protective behaviors, in ways that recognize gender vulnerability and cultural realities.

- Increase understanding of the social context of vulnerability of young people. Programs targeting young people need to go beyond increasing knowledge about transmission routes, to increasing young people's awareness of how social and cultural factors increase their vulnerability or limit their ability to adopt protective behaviors. Recognition and discussion of difficult issues such as intergenerational sex, exchange of gifts and money for sex, and forced sex are also important in ensuring that programs for young people address all aspects of their vulnerability.

- Address gender stereotypes and mistrust in relationships. Young people of both sexes often blame each other for the spread of HIV because of a general feeling of mistrust in relationships. Gender stereotypes, which particularly prevent females from taking greater initiative to protect themselves, need to be addressed. There is an urgent need to find ways of building trust and responsibility for HIV prevention between young people in a relationship.

- Increase access to condoms for sexually active youth in rural areas. Access to condoms in rural areas remains a barrier to adequate condom use for sexually active young people. Even in areas where condoms are available and affordable, young people often do not feel comfortable about 
obtaining them from places such as rural health centers often because of opposition from adults. Condom promotion must be sensitively targeted to young people who need them, especially those who are sexually active. Because of the problems of access and resistance to condoms in some settings, and the importance attached to abstinence, effective strategies to promote and sustain abstinence are vital complements to condom promotion strategies as part of a comprehensive prevention program.

- Ensure youth are able to care for people living with HIV and AIDS safely, even as part of prevention efforts. Young people who are well informed about HIV and AIDS know that they cannot contract HIV by casual contact. However, there is a gap between this knowledge and the reality of caring for someone who has AIDS. While many youth programs focus on prevention alone, the reality is that many young people are caring for people living with HIV and AIDS in their own homes and communities, and questions of safety cannot be ignored. It is important that youth prevention programs in high endemic areas combine prevention and care to ensure that youth caregivers are not at risk of contracting HIV or other infections. 


\section{Hgrizons}

\section{References}

Central Statistical Office (Zambia), Central Board of Health (Zambia) and ORC Macro. 2003. "Zambia demographic and health survey 2001-2002." Calverton, MD, USA: Central Statistical Office, Central Board of Health, and ORC Macro.

Central Statistical Office (Zambia), Ministry of Health (Zambia), and MEASURE Evaluation. 2002. "Zambia sexual behaviour survey 2000." Central Statistical Office and Ministry of Health, Government of the Republic of Zambia, Lusaka, Zambia, USAID, Lusaka, Zambia, and MEASURE Evaluation, USA, April 2002 www.cpc.unc.edu/measure/publications/pdf/tr-02-12.pdf.

Macwan'gi, M., M. Sichone, and P.N. Kamanga. 1994. "Women and AIDS in Zambia: Situation analysis and options for HIV/AIDS survival assistance." Study commissioned by the Ministry of Health, National AIDS Prevention and Control Programme, Zambia.

UNAIDS, UNICEF, and WHO. 2002. "Zambia : Epidemiological fact sheets on HIV/AIDS and sexually transmitted infections 2002 update."

www.who.int/emc-hiv/fact_sheets/pdfs/Zambia_EN.pdf 


\section{Hgrizons}

Horizons is a global operations research program designed to:

- Identify and test potential strategies to improve HIV/AIDS prevention, care, and support programs and service delivery.

- Disseminate best practices and utilize findings with a view toward scaling up successful interventions.

\section{(2 Population Council}

Horizons is implemented by the Population Council in collaboration with

- International Center for Research on Women (ICRW)

- International HIV/AIDS Alliance

- Program for Appropriate Technology in Health (PATH)

- Tulane University

- Family Health International (FHI)

- Johns Hopkins University

For more information, please contact:

Horizons Program, Communications Unit 4301 Connecticut Avenue, NW Suite 280 Washington, DC 20008 USA

Tel: 202-237-9400

Fax: 202-237-8410

Email: horizons@pcdc.org www.popcouncil.org/horizons 